Article

\title{
Effect of the Common Solvents on UV-Modified Photopolymer and EPDM Flexographic Printing Plates and Printed Ink Films
}

\author{
Tamara Tomašegović ${ }^{1, *}$, Sanja Mahović Poljaček ${ }^{1, *}$, Maja Strižić Jakovljević ${ }^{1}$ and \\ Raša Urbas ${ }^{2}$ (D) \\ 1 Faculty of Graphic Arts, University of Zagreb, Getaldićeva 2, 10000 Zagreb, Croatia; maja.jakovljevic@grf.hr \\ 2 Faculty of Natural Science and Engineering, University of Ljubljana, Aškerčeva cesta 12, SI-1000 Ljubljana, \\ Slovenia; rasa.urbas@ntf.uni-lj.si \\ * Correspondence: ttomaseg@grf.hr (T.T.); smahovic@grf.hr (S.M.P.)
}

Received: 10 December 2019; Accepted: 1 February 2020; Published: 4 February 2020

check for updates

\begin{abstract}
The aim of this research was to analyze the influence of the solvents commonly used in flexography on photopolymer and ethylene propylene diene monomer (EPDM) flexographic printing plates and prints. EPDM plates are recommended when the reproduction process includes a higher amount of the solvents or aggressive solvents. Since additional UV treatment of flexographic printing plates could decrease the interaction between the plate and solvent, photopolymer and EPDM plates were treated with varied UV radiation and exposed to different types of solvents. Effects of the UV treatment and of the solvents on printing plate properties and on prints were analyzed. Results show that EPDM plates are more resistant to solvents in terms of the degree of swelling; however, surface properties of the plates were affected for both plate materials. In addition, the degree of swelling and increased hardness due to UV radiation were crucial for changes of the width of printed lines, and altered surface free energy affected the thickness of deposited ink film for both plate materials. Therefore, depending on the qualitative requirements of specific printed film, the duration of UV treatment can be adjusted for use with specific types of printing plate and solvent.
\end{abstract}

Keywords: flexography; photopolymer; EPDM; UV treatment; swelling; surface free energy; line width; ink film thickness

\section{Introduction}

Technological processes for the deposition of ink and coating films have been extensively developing in recent years. Various materials and printing techniques are being optimized with the aim of obtaining printability and high quality of different conventional and functional ink/coating films [1-3]. Flexography is a progressive printing technique highly applicable in packaging industry and in printing of different functional films and coatings [3-9]. It is a rotary printing method in which the printing plate is the central component transferring the printing ink directly onto the printing substrate. In addition to flexography, there are other conventional printing techniques that can be used for deposition of different types of films and coatings, such as screen printing and gravure printing [10-13]. The advantage of flexographic printing is the ability to print on different types of substrates and the formation of a printed film of certain properties. These advantages have led to a significant expansion of the application of this printing technique [14-17]. As the printing plate is the central component between the ink and the substrate in the ink transfer process, it has a significant influence on the quality of transferred ink film [18,19].

Published studies in the field of flexography studied the properties of printing inks and printing substrates [20-23], whereas the area of analysis of the properties of printing plates and their possible 
changes during the printing process has not been studied enough. Printing plates used in the modern flexographic process are primarily made of different polymeric and elastomeric materials [19]. During the printing process, the printing plate first has to adsorb the printing ink from an anilox roller and secondly has to transfer the ink to the substrate. Printing inks come in three main varieties: Solvent-based, water-based, and UV curable inks $[15,19]$. The most frequently used solvents in printing inks are ethyl acetate, ethanol, and methyl ethyl ketone [24,25]. During the printing process, the printing plate is continuously in contact with solvents from printing inks. Through this interaction, the solvents can have a noticeable impact on the printing plate, causing the swelling of the plate and consequently changes in its surface and mechanical properties. Furthermore, different types of solvents are used for washing and removal of the ink residues from the printing plate's surface after the printing process has been carried out, in order to store and reuse the printing plates. Washing agents for flexographic printing plates often contain solvents such as ethyl acetate, which can cause the swelling of the printing plate's surface as well and can even cause the dissolution of the printing plate surface to a certain extent. The interactions that happen between the printing plates and solvents used in flexography and their influence on the deposited ink film quality have not been studied enough and require a detailed analysis for better understanding. Published research in this area was conducted to define the effect of commonly used solvent mixtures on molded printing plates made of natural rubber and various photopolymer plates [26]. The research was directed at detection of changes in hardness and weight change of printing plate materials immersed in different solvents over time. The solvents used in this experiment were mixtures of different amounts of propyl alcohol (1-propanol), propyl acetate, and Lactol spirits (hydrocarbon). It was concluded that the printing plates of similar polymer composition show similar changes in the degree of softening; it was also established which mixtures of different Lactol spirits and normal propyl acetate added to alcohol affected the plates the most. This research has shown that the interactions in the contact line of the printing plate surface and the solvents can cause the swelling on the surface structures of the printing plates. Furthermore, research exploringthe influence of swelling of the printing plate surface on the deposited printed film has not been published yet. There is no recent published research in the field of application of new materials for the production of printing plates and their interaction with solvents.

There are number of printing plate properties that have an influence on the printing ink adsorption and its transfer to the substrate. Surface free energy of the printing plate and the hardness are two of the most influential parameters [27-30]. If one of those parameters is changed due to the interaction of the printing plates with solvents, the adsorption of the inks will be changed, resulting in obtaining printed films of altered qualitative properties. On the other hand, previous research in the area of printing plates has proven that by additional surface treatment of the printing plate's surface, it is possible to adjust these properties of the plates, causing the optimal interfacial interaction between the plate and printing ink [31-33]. It was shown that additional UV treatment of the printing plate surface could be used as a method for obtaining a maximal possible quality in the reproduction process, and it can be used for adjustment of the printing plates' surface properties for deposition of different coatings. Since previous research investigated primarily photopolymer printing plates, this research used both photopolymer and ethylene propylene diene monomer (EPDM) plates, which have relatively recently been re-introduced to market as they are recommended for their resistance to various solvents.

\section{Materials and Methods}

In this research, surface modification of printing plates used in flexography (photopolymer and EPDM) by additional UV treatment was performed in order to analyze the influence of the common solvents on modified printing plates and printed ink films. Changes of the plate properties can cause adverse adsorption of the printing ink on the printing plate surface and influence the ink transfer onto the printing substrate, thereby forming a printed film of altered quality. The influence of UV treatment on the swelling resistance of the observed plates was analyzed and connected to the changes of qualitative properties of printed ink films. The surface free energy and hardness of the printing plate 
samples were measured, and swelling properties of the printing plate materials are discussed. SEM images of modified printing plate surfaces were obtained as well. The resulting printed films were analyzed to compare the effect of UV treatment and swelling on the properties of the deposited ink film. By measuring the widths of the printed lines and deposited ink film thickness, the relationship between the parameters of modified plates and obtained prints were defined.

\subsection{Production of the Flexographic Printing Plates}

In this research, two types of printing plates used in modern flexography were prepared: Photopolymer plates and EPDM printing plates. Photopolymer printing plate samples were based on laser ablation mask (LAMS), with a digital (computer to plate, CtP) production procedure [34]. The production process of photopolymer plates includes different phases of exposures of the photopolymer material to UV radiation that has the role of initiation and conduction of the photo-initiated crosslinking process in the photopolymer material. Composition of this type of printing plate includes different types of copolymers, the most common being styrene-butadiene-styrene (SBS) and styrene-isoprene-styrene (SIS) block copolymers; photoinitiators sensitive to UV radiation; plasticizers, which provide elastic properties; colorants; and other additives [35]. Photopolymer plates used in this research were SIS-based. Samples of the printing plates were produced by the standard procedure recommended by their manufacturer up to the post-treatment process (Figure 1). A cross-section of the used photopolymer plate is presented in Figure 1a. The LAMS mask covers the whole surface of the printing plate and enables the transfer of the image to the plate by laser ablation process. Production phases of those plates are presented in Figure 1b,g.

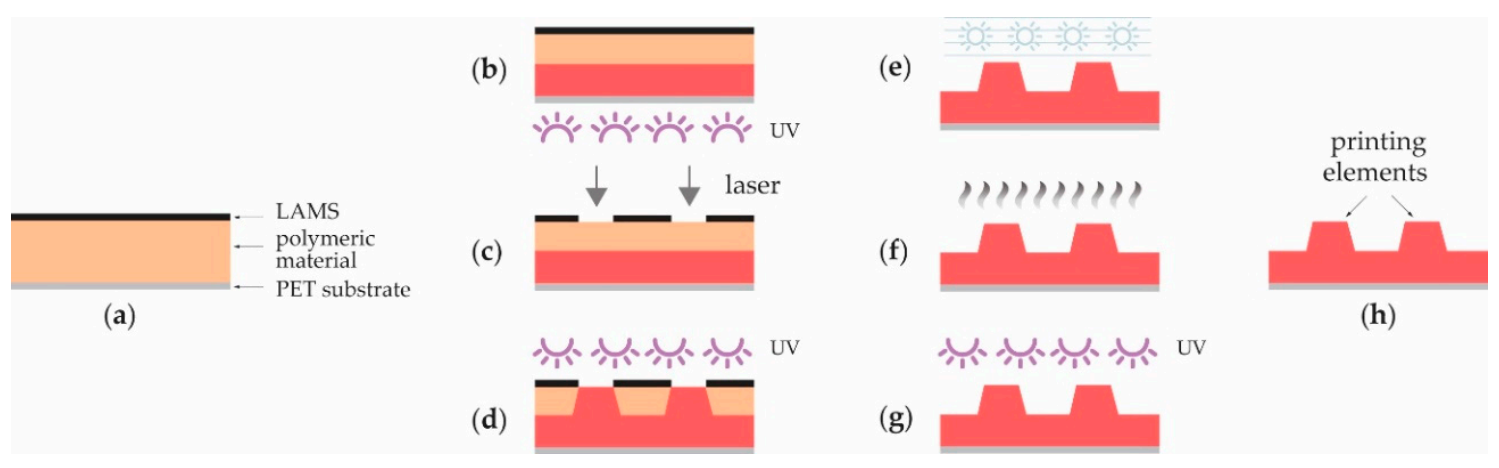

Figure 1. Production phases of the laser ablation mmask layer (LAMS)-based printing plate:

(a) Cross-section of the photopolymer sheet, (b) back exposure, (c) ablation of the LAMS mask,

(d) main exposure, (e) rinsing, (f) drying, (g) post-treatment, (h) finished plate.

In the first phase, a back exposure must be conducted through the base material to form a polymer layer that carries the image elements (Figure 1b). In the next phase, a LAMS mask is removed by laser ablation process to form image elements on the surface of the photopolymer material (Figure 1c). Figure $1 \mathrm{~d}$ presents the main exposure, where the image elements are formed by exposing the printing plate to UV radiation. Exposed parts of the polymer material crosslink and become insoluble in the rinsing solution (Figure 1e). The rinsing process removes the unexposed parts of the photopolymer material, followed by a drying process (Figure 1f). After the stabilization period, produced printing plate samples should be exposed to additional UV radiation (Figure 1g) in order to terminate the crosslinking process and obtain the optimal surface properties of the printing plate. This final UV exposure (post-treatment) is mandatory for photopolymer plates, and it defines the surface properties of the material (Figure 1h) [36]. Therefore, unlike the EPDM samples, the set of photopolymer samples prepared in this experiment does not have the "zero" sample without any UV post-treatment, since the plate is not finished and functional without the additional UV radiation. In this research, the plate samples were exposed to different durations/intensities of UV post-treatments. 
The production process of elastomeric rubber printing plates requires laser engraving of the elastomeric material in order to form an image in the printing plate [37-39]. Most of the laser engraved printing plates are made of synthetic rubber and include ethylene propylene diene monomer (EPDM) elastomers that are capable of absorbing laser radiation and becoming physically detached from the base material. The benefit of this process is in the natural environment because the process involves no ecologically harmful solvents at all. A section of the EPDM plate and its production phases are presented in Figure 2 [40]. On the base carrier, a compressible layer and an EPDM material were applied (Figure 2a). The compressible layer ensures good printing performance of the plate, and the EPDM material is used for formation of image in the printing plate. In the first step, the laser engraves the EPDM material and forms image elements in the printing plates (Figure 2b). In the next step, the washing process rinses away the ash residue from the printing plate's surface (Figure 2c).

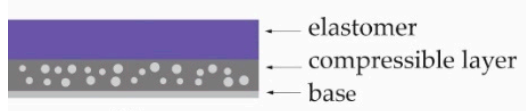

(a) (b)

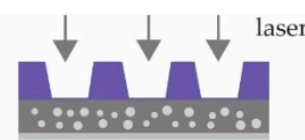

(c)

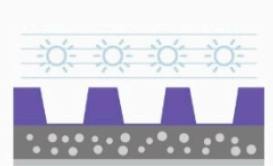

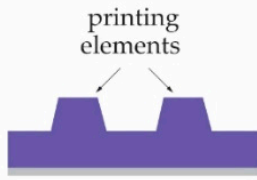

(d)

Figure 2. Production phases of the ethylene propylene diene monomer (EPDM) printing plate:

(a) Section of the printing plate, (b) laser engraving, (c) washing of the plate, (d) finished plate.

EPDM plates do not require any treatment by UV radiation, but as UV radiation has been proved as a useful tool for modification of the surface properties of EPDM in previous research [8], it was applied to these plates alongside the photopolymer ones [41].

For the purpose of this research, nine printing plates made of photopolymer material and nine made of EPDM material were prepared. Both types of printing plates had a height of $1.14 \mathrm{~mm}$. All samples of printing plates were produced by the standard procedures recommended by their manufacturer $[34,40]$. Photopolymer plates were prepared up to the post-treatment process. For the measurement purposes of the printed films, the test image was transferred to the printing plate surface consisting of positive and negative fine lines and a full tone image (Figure 3).

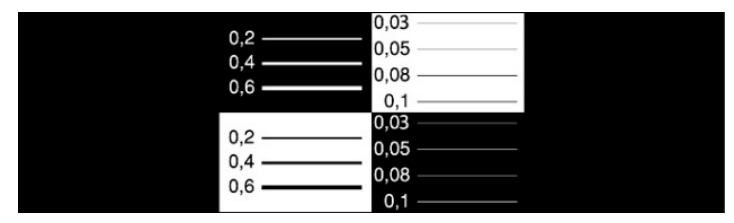

Figure 3. Test image transferred from the digital file to the printing plate.

\subsection{Surface Treatment of Printing Plates and Swelling Experiment}

Produced samples of polymer and EPDM printing plates were exposed to UV radiation in order to increase the crosslinking degree and to optimize their surface properties. Modification of the printing plates was performed by UV curing instrument Technigraf Aktiprint $\mathrm{L}$ with the emission of the UV source in the range from $210-380 \mathrm{~nm}\left(2870 \pm 5 \mathrm{~mW} / \mathrm{cm}^{2}\right)$ and $320-420 \mathrm{~nm}\left(1150 \pm 20 \mathrm{~mJ} / \mathrm{cm}^{2}\right)$ [42]. Printing plate samples were treated with $10 \times, 20 \times$, and $30 \times$ passes under the UV radiation source of $100 \%$ intensity and with $4 \mathrm{~m} / \mathrm{s}$ speed. As was shown in previous research, the additional UV treatment of the printing plates leads to the continued crosslinking process in the core of analyzed polymeric materials, affecting the mechanical and surface properties of the material as well $[32,33,43]$.

After the various UV treatments of all printing plates, the samples were divided into three groups, each group containing the samples with all three performed durations of UV treatments. They were 
immersed into the three most commonly used solvents in flexographic reproduction: Propylene glycol methyl ether (PGME or 1-methoxy-2-propanol, or methoxypropanol), an organic solvent mostly used as a solvent in printing inks; isopropyl alcohol (2-propanol or IPA); and Polywash solution, which is mostly used as a washing agent for printing plates [44,45]. It was expected that different solvents would affect photopolymer and EPDM materials used for printing plates to a varying degree. The method of material swelling has been used for the analysis of the printing plate-solvent interaction. For this purpose, Hansen solubility parameters (HSP) of the solvents were useful for understanding the solvent-polymer interaction. The basis of HSP is that the total energy of vaporization of a liquid consists of several parts: The dispersion forces $\left(\delta_{d}\right)$, permanent dipole-permanent dipole forces (polar forces $\left(\delta_{p}\right)$ ), and hydrogen bonding $\left(\delta_{h}\right)$. Cohesion energy must be the sum of the individual energies which make it up. The square of the total (or Hildebrand) solubility parameters is the sum of the squares of the $d, p$, and $h$ components (Equation (1)) [46].

$$
\delta^{2}=\delta_{d}^{2}+\delta_{p}^{2}+\delta_{h}^{2}
$$

The closer the solubility parameters of observed materials and solvents, the more likely that material is to dissolve in that solvent. Table 1 presents the Hansen solubility parameters of solvents used in this research. Methoxypropanol, IPA, and Polywash solution were used as swelling agents due to the different types and strengths of their molecular bonds and therefore different impact on the printing plate materials. Swelling measurements were performed by gravimetric method [47] in a controlled environment with a constant temperature of $25^{\circ} \mathrm{C}$.

Table 1. Hansen solubility parameters of solvents used in experiment.

\begin{tabular}{cccc}
\hline & $\boldsymbol{\delta}_{\mathbf{d}}\left(\mathbf{J} / \mathbf{c m}^{\mathbf{3}}\right)^{\mathbf{1 / 2}}$ & $\boldsymbol{\delta}_{\mathbf{p}}\left(\mathbf{J} / \mathbf{c m}^{\mathbf{3}}\right)^{\mathbf{1 / 2}}$ & $\boldsymbol{\delta}_{\mathbf{h}}\left(\mathbf{J} / \mathbf{c m}^{\mathbf{3}}\right)^{\mathbf{1 / 2}}$ \\
\hline Methoxypropanol & 15.6 & 7.2 & 13.6 \\
2-propanol (IPA) & 15.8 & 6.1 & 16.4 \\
Polywash: & - & - & - \\
4-hydroxy-4-methylpentan-2-one & 7.7 & 4.0 & 5.3 \\
Butyl cellosolve & 16.0 & 7.6 & 12.3 \\
\hline
\end{tabular}

Printing plate samples were immersed in methoxypropanol, IPA, and Polywash for period of $6 \mathrm{~h}$ in total, after which the weighing showed that the equilibrium of swelling was reached. Normalized degrees of swelling $\left(M_{t}\right)$ for control periods of 5, 15, 30, 60, 90, 120, 180, 240, 300, and $360 \mathrm{~min}$ of immersion were calculated using Equation (2):

$$
m_{t}=\frac{m_{t}-m_{0}}{m_{0}} \times 100 \%
$$

where $m_{t}$ stands for the mass of the swollen polymer at a time $t$, and $m_{0}$ for the mass of the dry polymer sample before the immersion. After the swelling experiment, samples were dried at $25^{\circ} \mathrm{C}$ and $55 \%$ relative humidity for $24 \mathrm{~h}$ prior to conducting the following experiments. Swelling analysis of photopolymer and EPDM materials in solvents was used to get a detailed insight into the interaction of solvents and printing plates after the UV treatment.

\subsection{Measurements of Photopolymer and EPDM Hardness}

Hardness is the parameter influencing the deformation of the printing plate during the engagement in the printing process and is related to elastic deformation of the plate. In the production of the printing plates, the hardness of the printing plates may vary due to the crosslinking process in the printing plates [33]. In order to monitor the changes in the flexographic printing plate's quality, changes in hardness of flexographic printing plates produced under different UV treatment conditions before and after the immersing of the printing plates in solvents were examined. A ZwickRoell durometer 
with Shore A scale was used for the hardness measurements, which were performed according to ISO 7619-1 standard [48].

\subsection{Determination of Surface Free Energy}

Surface free energy (SFE) of observed samples was calculated by using the sessile drop method and DataPhysics OCA 30 Goniometer [49]. On the printing plate samples, contact angles $(\theta)$ of three different probe liquids of known surface fee energy $\left(\gamma_{1}\right)$ were measured at $25^{\circ} \mathrm{C}$ : Demineralized water, glycerol, and diiodomethane. Contact angle and SFE of the probe liquids are the parameters that were used to calculate SFE of the printing plate samples. Eight measurements of contact angles were performed for each probe liquid on plate samples. The shape of the probe liquid drops was a spherical cap, and the volume of the drops was $1 \mu \mathrm{L}$. All measurements of the contact angles on the samples were performed in the same moment after the drop touched the printing plate surface, with a delay of $4 \mathrm{~s}$, and the average value was calculated. Surface free energy was calculated using the Owens, Wendt, Rabel, and Kaelble (OWRK) calculation method [50,51]. The OWRK method is the most commonly used method for determination of SFE of polymer materials, along with their polar $\left(\gamma^{p}\right)$ and dispersive $\left(\gamma^{d}\right)$ parts applicable for polymer, aluminum, and coatings characterization, which is calculated using Equation (3):

$$
\frac{(1-\cos \theta) \cdot \gamma_{s}}{\sqrt[2]{\gamma^{d}{ }_{l}}}=\sqrt{\gamma^{p_{s}}} \sqrt{\frac{\gamma^{p_{l}}}{\gamma^{d_{l}}}}+\sqrt{\gamma^{d_{s}}}
$$

where $\gamma_{s}$ is surface tension of the solid, $\gamma_{l}$ is the surface tension of the liquid, $\gamma^{d}$ is the dispersive part of surface tension, $\gamma^{p}$ is the polar phase of surface tension, and $\theta$ is the contact angle.

\subsection{Scanning Electron Microscopy (SEM Microscopy)}

Surfaces of the plate samples were observed by SEM microscope SEM JSM-6060 LV (Jeol, Tokyo, Japan). The instrument is designed for surface, morphology, and topography studies as well as for determination of particle size. An SEM image is made by secondary electrons, which are detected in the sample by the primary beam that is scanning the surface point by point. Non-conductive materials are preliminarily coated with gold, which prevents static charge on the surface. The microscope includes an electrical gun, magnification unit, image generator, condensation and objective lenses, electron collector, and vacuum system. Samples of great value can be observed without coating in a low vacuum mode. For the purpose of image analyses, samples were fixed on a specimen stub and coated (with high vacuum evaporation) with an ultra-thin layer of gold. Images were captured at different magnifications.

\subsection{Printing Process and Measurements of the Properties of the Printed Ink Film}

The printing process was performed in laboratory by means of IGT Printability Tester F1 [52]. Printing was performed on Melinex®polyester films (New Berlin, WI, USA) with UV curable printing ink, $400 \mathrm{~L} / \mathrm{cm}$ anilox of $2.5 \mathrm{~mL} / \mathrm{m}^{2}$, standard printing pressure of $150 \mathrm{~N}$, and speed of $0.3 \mathrm{~m} / \mathrm{s}$.

Printed ink film thickness was measured by means of a SaluTron D4-Fe device (Frechen, Germany) [53]. The SaluTron D4-Fe works on the magnetic induction principle and measures all nonmagnetic coatings such as synthetics, lacquers, enamels, copper, chromium, and zinc on steel or iron. The results of the printed film thickness were used to identify the influence of printing plate parameters, subjected to change during variations of the UV treatment process and swelling, on the printed ink film.

Microscopy of printed elements was performed by means of an Olympus BX51 microscope (Tokyo, Japan) at magnification of $200 \times$ in order to define the influence of additional UV treatment on definition of fine lines. Obtained images were used for in-software measurements of the width of printed lines, 
both in positive and in negative (Figure 3). In this paper, the widths of the $0.2 \mathrm{~mm}$ positive and $0.2 \mathrm{~mm}$ negative lines are presented.

\section{Results and Discussion}

In this section, results of the analysis of printing plate samples and the analysis of the properties of the prints obtained by modified printing plates exposed to the solvents are presented.

\subsection{Hardness of Printing Plates}

In Figure 4, one can see the results of the hardness measurements. The dependence of the hardness on the UV treatment of the samples is presented for each photopolymer printing plate sample exposed to different solvents. The $y$-axis shows the numerical values of the hardness on the Shore A scale.

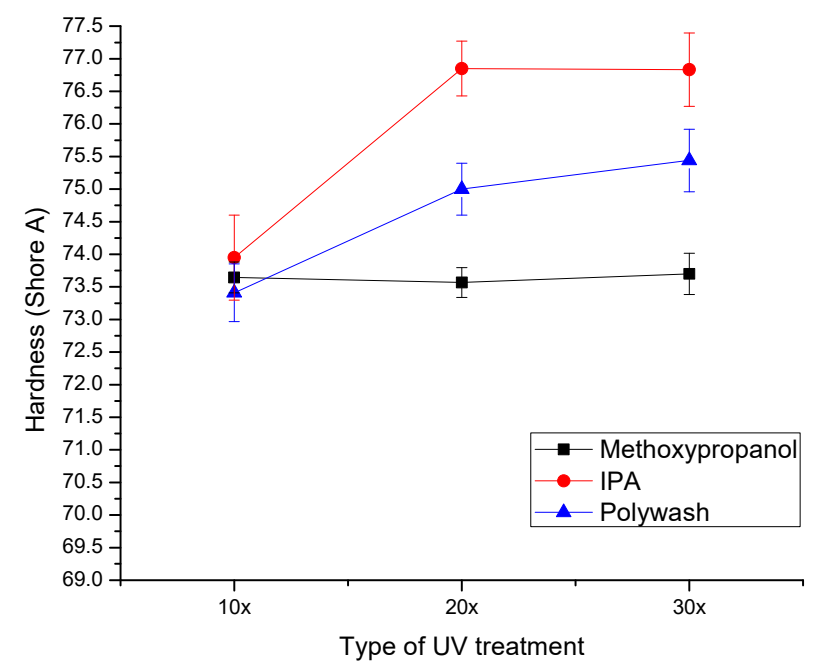

Figure 4. Hardness of the modified photopolymer printing plate samples after exposure to solvents.

The hardness of the photopolymer sample not treated by any solvent is $\sim 72$ Shore A [43].

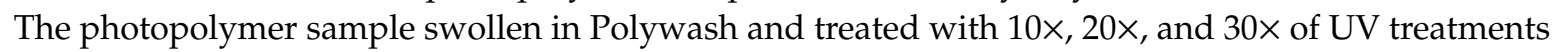
presented increased hardness, up to 73.7 Shore A. Generally, the increased hardness of the material is directly connected to the increased crosslinking degree due to the UV treatment and increased polymer network density. The hardness of the photopolymer sample swollen in IPA increases up to 76.8 Shore A with the prolonged UV treatment. The hardness of the photopolymer sample exposed to methoxypropanol presents no significant changes, regardless of the duration of the UV treatment. These results indicate that methoxypropanol actually has the highest impact on the photopolymer printing plate in terms of alterations of the material. There is evidently residual solvent in the photopolymer structure after the swelling, since the hardness of the photopolymer printing plate should increase after the prolonged UV treatment due to the further crosslinking in the material [43,54]. Methoxypropanol prevents the increase of the hardness, since any solvent remaining inside the polymer network after swelling affects the hardness with a negative mark. The denser the polymer network is (due to the additional crosslinking), the less expressed the penetration of the solvent is in its structure $[55,56]$.

Increase of the hardness of the printing plate influences the ability of the printing plate to deform and adjust to the printing substrate during the printing process. Printing plates with hardness increased by additional UV treatment can therefore be used for deposition of ink film onto smooth, non-porous substrates. If the printing process is conducted using the ink that has methoxypropanol in its composition, it is important to be aware of the effect methoxypropanol has on the UV-treated material hardness.

Figure 5 presents the results of the hardness measurements of modified and solvent-exposed EPDM printing plates. 


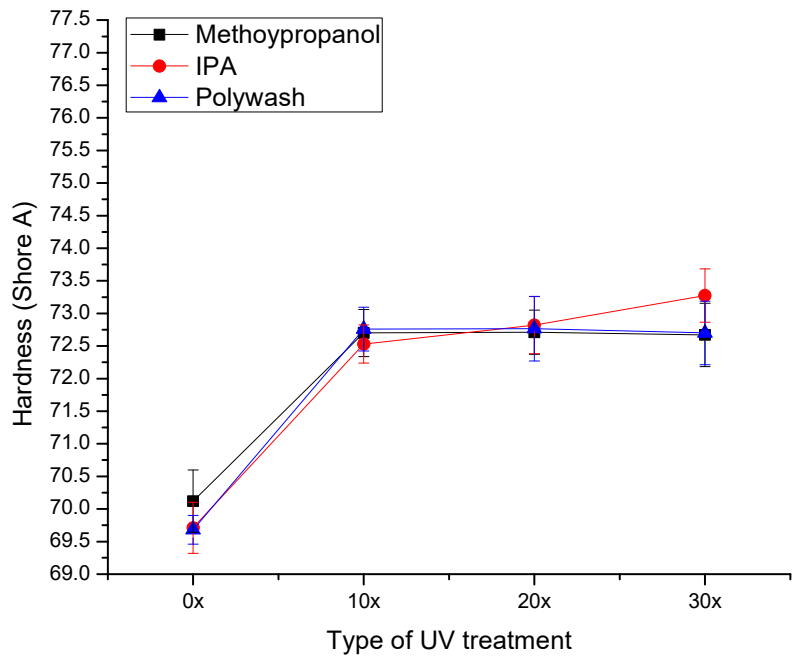

Figure 5. Hardness of the modified EPDM printing plate samples after exposure to solvents.

When comparing Figures 4 and 5, it is immediately noticeable that the hardness of the UV-treated EPDM printing plate samples after immersion in all solvents shows an approximately similar value regardless of the duration of the UV treatment. The measured hardness of the EPDM sample not treated by any solvent was $\sim 70$ Shore A. Preliminary measurements showed that the hardness of the UV-exposed EPDM printing plate (up to $30 \times$ UV treatment) increases up to 73 Shore A prior to the immersion in solvents. The highest hardness is present for the sample treated with $30 \times \mathrm{UV}$ treatment and after swelling in IPA (73.28 Shore A). This indicates the resistance of the bulk of additionally cross-linked polymer to the influence of IPA. Any significant changes important for the ink deposition process after the exposure of the EPDM printing plate to solvents are therefore to the surface properties.

\subsection{Surface Free Energy of Printing Plates}

Figure 6 presents the results of the calculations of the total surface free energy (SFE) of the photopolymer samples after UV treatment and swelling in the solvents. Polar component of SFE of both types of printing plates (photopolymer and EPDM) was negligible $(\sim 0.1 \mathrm{mN} / \mathrm{m})$, and therefore the dispersive and total surface free energy are almost equal in amount.

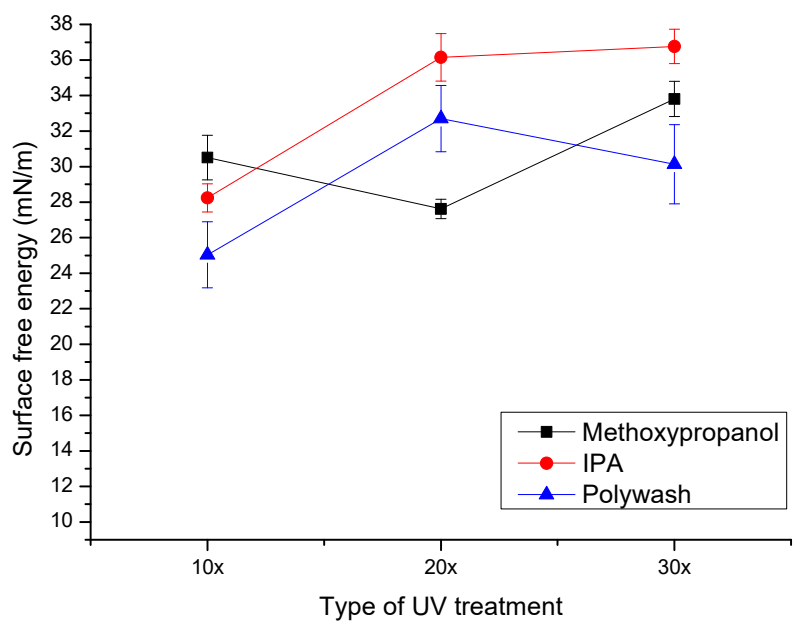

Figure 6. Surface free energy of the modified photopolymer printing plate samples after exposure to solvents.

A standard sample of this type of photopolymer printing plate not exposed to any solvent has total SFE of $\sim 30 \mathrm{mN} / \mathrm{m}$ [54]. Our preliminary measurements have shown that the radiation of $10 \times \mathrm{UV}$ 
treatment corresponds to the standard SFE of a finished photopolymer plate. Exposure to Polywash causes the expressed decrease of SFE for the photopolymer that has not been additionally crosslinked by prolonged UV treatment but does not influence the trend of SFE after longer UV treatments [43]. Furthermore, the increase of SFE is not continuous for samples exposed to methoxypropanol-there is a prominent decrease of SFE for the sample treated by 20× UV. Due to the more complex changes that occur on the surface of photopolymers as a result of UV treatment (formation of byproducts, breakage of double bonds, migration of protective waxes of low molecular weight to the surface after specific exposure to UV radiation) [57-59], there are different durations of UV treatment that cause a stronger interaction between the individual solvent and the photopolymer sample. Therefore, for these samples, there is a specific change in the otherwise predetermined and investigated trend of changes of SFE [41,43]. A decrease in SFE for this type of sample generally means the migration of waxes to the surface or the beginning of degradation of the material. The analysis of swelling dynamics therefore gives a more detailed insight into the changes taking place on the samples. Figure 7 presents the trends of changes of SFE of EPDM printing plates.

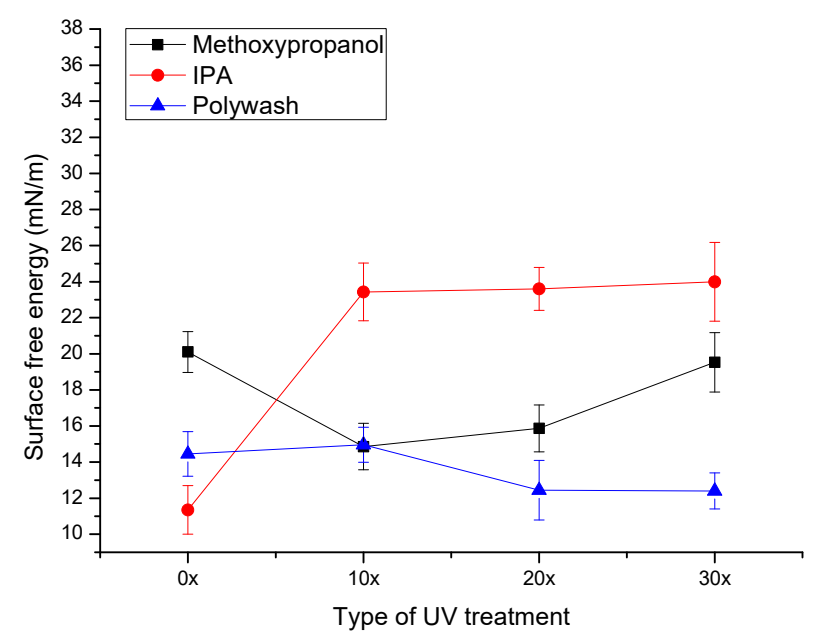

Figure 7. Surface free energy of the modified EPDM printing plate samples after exposure to solvents.

A standard sample of the EPDM printing plate not treated with additional UV treatment or exposed to any solvent presented measured SFE of $\sim 20 \mathrm{mN} / \mathrm{m}$. It is important to note that flexographic printing plates come in a wide range of SFE, from $\sim 20 \mathrm{mN} / \mathrm{m}$ to $\sim 40 \mathrm{mN} / \mathrm{m}$, each suitable for use with specific ink and for the deposition of the films/coatings of different properties and in respect to the substrate used to print on [32]. Furthermore, in the preliminary research, EPDM printing plates did not present a significant increase of SFE after the UV radiation. They even displayed a slight decrease of SFE, which can be explained by the migration of the protective compounds such as antiozonides and antioxidants in their composition to the surface. In Figure 7, it is visible that the exposure to Polywash after the UV treatment caused the decrease of the SFE compared to the nominal value even for the sample not treated with any UV radiation. The decrease of SFE can be explained by the migration of the compounds to the surface of the printing plate, rather than to any noticeable dissolution of the plate, as is visible from the results of the swelling experiments. Methoxypropanol influences the nominal SFE values of $20 \mathrm{mN} / \mathrm{m}$ for the samples of $10 \times$ and $20 \times$ of $U V$ treatment by decreasing them under nominal values due to the interactions between the solvent and compounds on the printing plate's surface. The sample not treated by UV radiation and immersed in IPA shows the lowest SFE, with a significant increase for longer UV treatments. However, the increased SFE of UV-treated EPDM printing plates also indicates the changes of the surface properties due to the interaction with IPA, specifically because of the slight partial dissolution of the material (discussed in Section 3.3). 


\subsection{Swelling of Printing Plates}

Swelling results of photopolymer and EPDM samples in solvents are shown in Figures 8-10. Photopolymer plate samples are marked with $\mathrm{P}$, and EPDM samples with $\mathrm{R}$, alongside the numerical index of UV treatment.

The normalized degrees of swelling present the percentage of increase/decrease in sample weight between 0-360 min of the immersion in methoxypropanol (Figure 8). Negative degree of swelling indicates the partial dissolution of the immersed material. Due to the obvious pronounced penetration of methoxypropanol in photopolymer plate (with the degree of swelling up to 5.7\%), it can be concluded that solubility parameters of methoxypropanol are the closest to the parameters of the photopolymer among the used solvents. This can cause problems during the printing (methoxypropanol is an integral part of some printing inks). Specifically, because of the residual methoxypropanol in the photopolymer material, printing elements on the plate can deform. The degree of swelling of the photopolymer in methoxypropanol for different samples corresponds inversely to the SFE trends for different durations of the UV treatment (Figure 4). When SFE of the photopolymer is highest (for the sample treated with $20 \times$ UV treatment), the penetration of methoxypropanol in the material is less expressed and normalized degree of swelling is lowest.

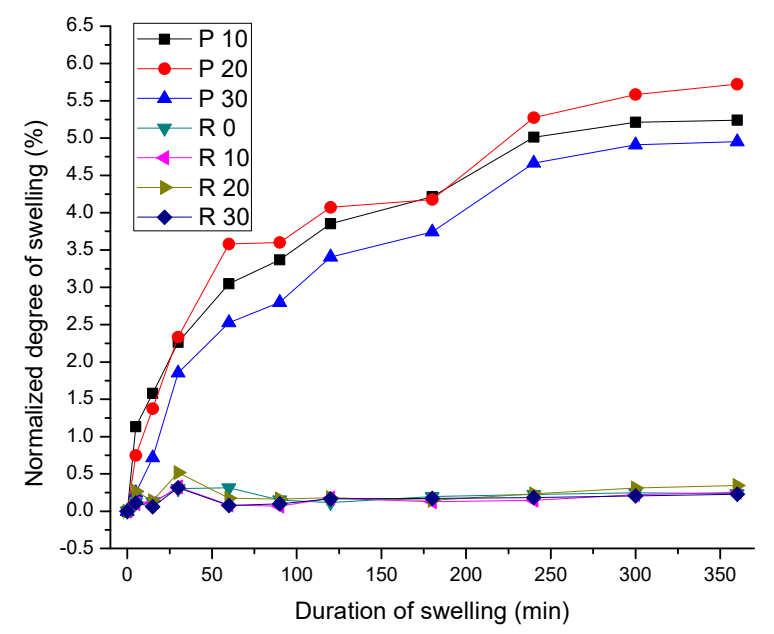

Figure 8. Normalized degree of swelling of the modified photopolymer printing plate samples in methoxypropanol.

On the other hand, the degree of swelling of the EPDM printing plate in methoxypropanol is negligible $(0.34 \%)$. Therefore, for the reproduction process using methoxypropanol, the use of the EPDM printing plate during the longer exposure to this solvent can be recommended in terms of the safety regarding the deformation of printing elements on the plate.

Figure 9 shows the normalized degrees of swelling in IPA. As can be seen, photopolymer samples treated with $10 \times$ and $20 \times$ of the UV treatment show increased compatibility with IPA in terms of interactions compared to the sample treated with $30 \times \mathrm{UV}$ treatment. This can be concluded because of the higher normalized degree of swelling than for the sample treated with $30 \times$ of UV treatment. The changes in the degree of swelling for samples treated with different durations of UV radiation follow the usual trend of UV-treated photopolymer printing plates [60], and the maximum swelling degree does not exceed $1.66 \%$. Therefore, it can be concluded that IPA does not significantly affect the structure of the photopolymer printing plate during the prolonged exposure and is safe to use in terms of its effect on the quality of the printing plate.

On the other hand, IPA slightly dissolves the EPDM printing plate, which can be concluded due to the negative degree of swelling (up to $-0.1 \%$ ). In order for the IPA to dissolve the EPDM printing plate sample, it first has to penetrate its surface. This happens in the first $5 \mathrm{~min}$ of the swelling experiment, causing the initial positive normalized degree of swelling. After that, regardless of the UV treatment, 
slight partial dissolution observable in the loss of weight occurs. Since the negative degree of swelling is of low value, it can be concluded that an additive in the plate has been dissolved.

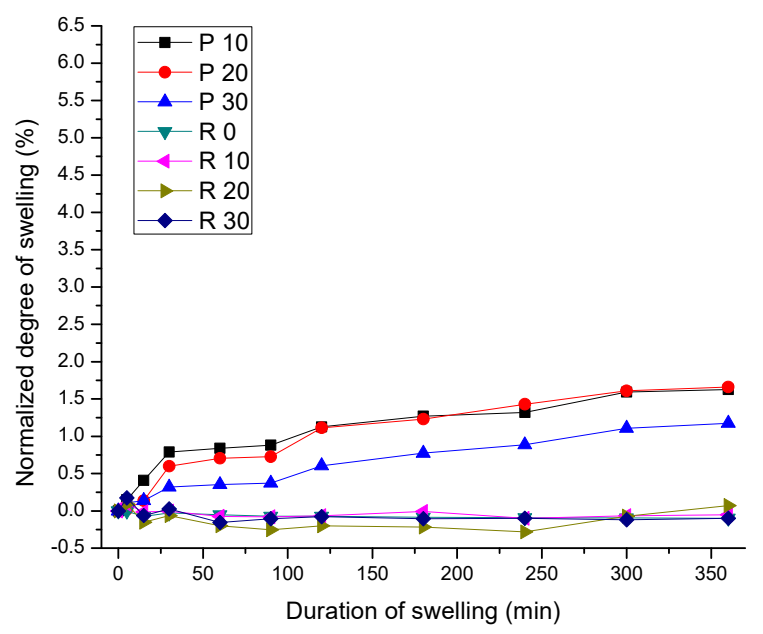

Figure 9. Normalized degree of swelling of the modified photopolymer printing plate samples in IPA.

Figure 10 presents the normalized degrees of swelling of the samples immersed in Polywash, the universal cleaning solution for flexographic printing plates. For photopolymer samples, swelling degrees are very similar to those in IPA but are somewhat more pronounced. The weakest interactions between solvent and photopolymer are again present for the sample treated with $30 \times \mathrm{UV}$ treatment- the sample that is additionally crosslinked compared to other photopolymer samples as a result of the prolonged UV treatment. The maximal degree of swelling is $2.1 \%$, which is still acceptable for the use of solvent in the reproduction process.

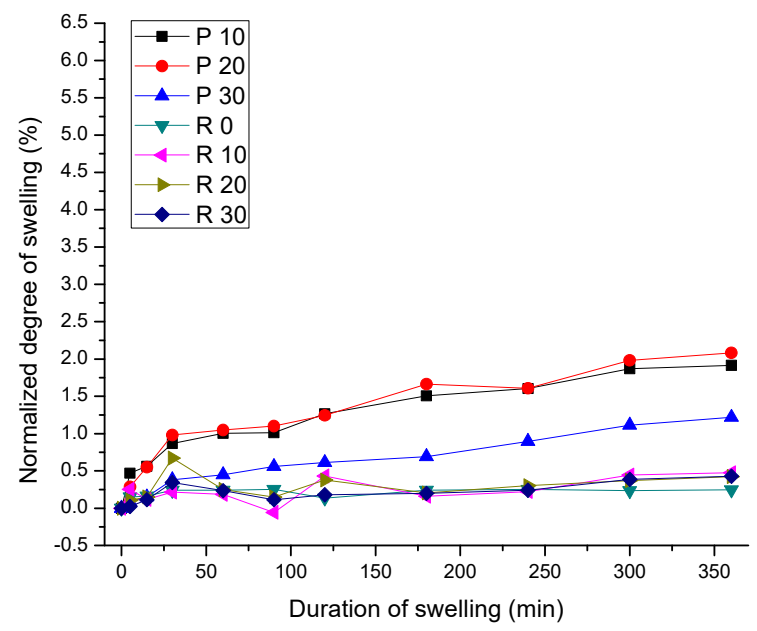

Figure 10. Normalized degree of swelling of the modified photopolymer printing plate samples in Polywash.

Unlike IPA, Polywash does not partially dissolve the EPDM printing plate, but causes minor swelling (up to $0.47 \%$ ), indicating that the additional UV treatment actually enhances the penetration of Polywash in the EPDM printing plate and should be avoided in this case.

\subsection{SEM Images of Printing Plates}

Figures 11-17 present the chosen surfaces of the printing plate samples before (Figure 11) and after the swelling experiments (Figures 12-17). The scale bar of $10 \mu \mathrm{m}$ is present on all images. 


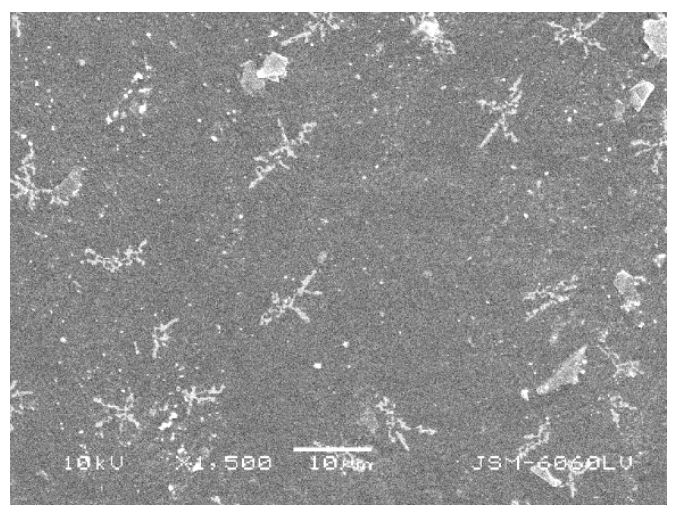

(a)

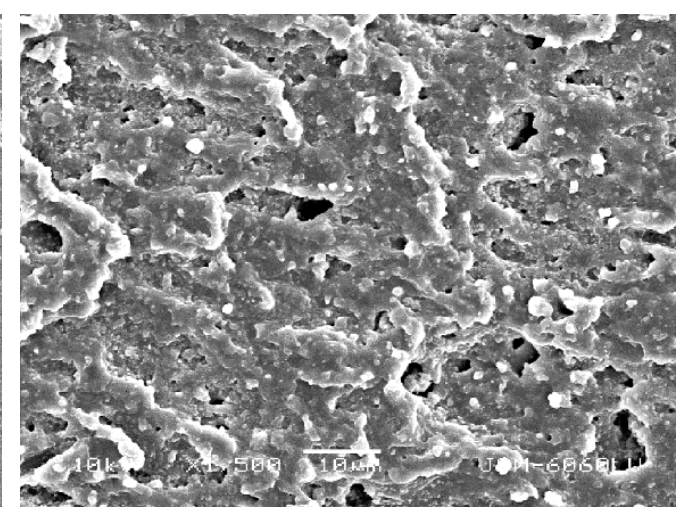

(b)

Figure 11. SEM images of printing plate samples before the exposure to solvents: (a) Photopolymer with $10 \times$ UV treatment, (b) EPDM with $0 \times$ UV treatment.

Figure 11 is presented as a reference to the appearance of the photopolymer and EPDM surfaces prior to any exposure to the additional UV radiation or to solvents. It is visible that photopolymer and EPDM samples have different surface morphologies, with the photopolymer surface being smoother and displaying inhomogeneity, while the EPDM surface displays porous characteristics.

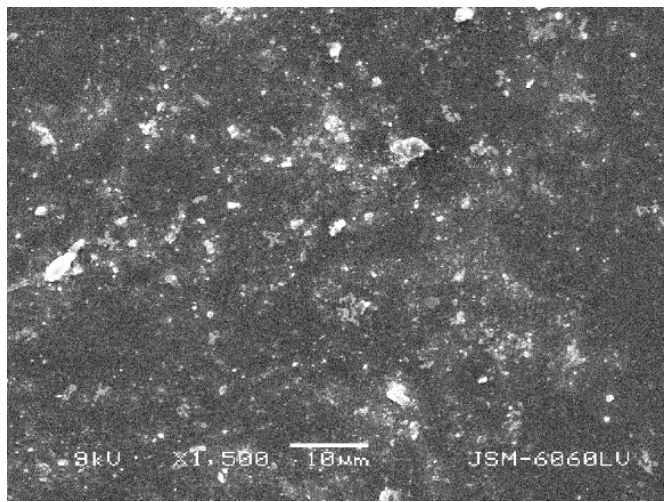

(a)

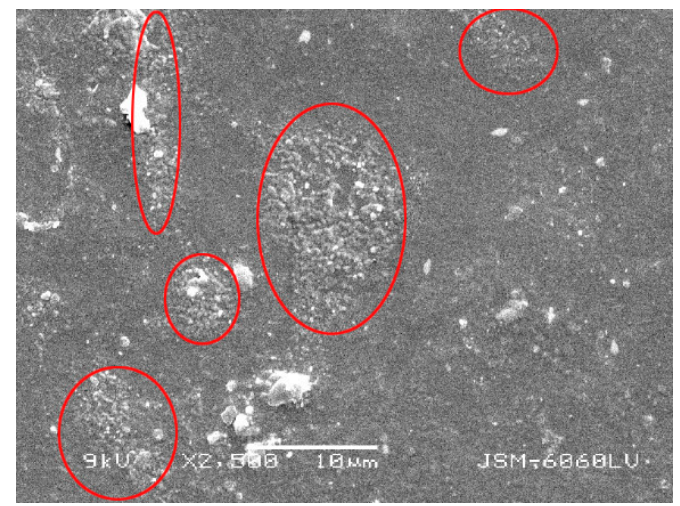

(b)

Figure 12. SEM images of photopolymer plate samples after swelling in methoxypropanol: (a) $10 \times \mathrm{UV}$ treatment, (b) 30× UV treatment

After swelling in methoxypropanol (Figure 12), changes in surface morphology are visible. They can be explained by the interaction/reaction between the solvent and additives in the printing plate that migrate to the surface when the photopolymer is exposed to outer stimuli such as UV radiation or solvent. Moreover, the effect of the expressed swelling in methoxypropanol may be seen in Figure 12b. Since the maximal normalized degree of swelling for photopolymer samples is $5.7 \%$, and since the flexographic photopolymer primarily possesses non-polar bonds, it can be concluded that solubility parameters of methoxypropanol are closest to those of the photopolymer material among the used solvents. In the long press run, this could significantly influence the qualitative properties of the deposited ink film in terms of the deformation of the printed fine elements and the transfer of the printing ink to the substrate.

Swelling of photopolymer samples in IPA (Figure 13) results in alterations to the surface morphology too (marked by red arrows). This expressed interaction with IPA is not visible in the results of the swelling but in the changes of SFE. Prolonged exposure of the photopolymer to UV radiation causes an increased number of polar groups in the surface of material, $\mathrm{C}=\mathrm{O}$ being expressed for this type of photopolymer [43]. $\delta_{\mathrm{h}}$ of IPA is the highest among the used solvents (Table 1 ), and since $\mathrm{C}=\mathrm{O}$ is a moderate acceptor for hydrogen donors [61], the effect of IPA on the additionally UV-treated photopolymer surface is significant. 


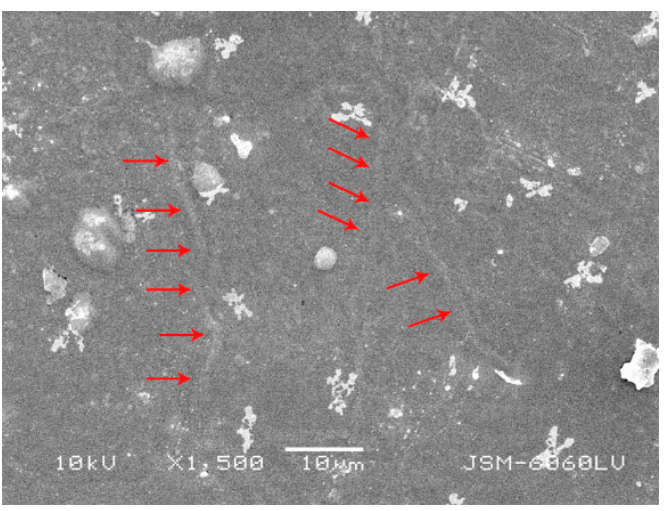

(a)

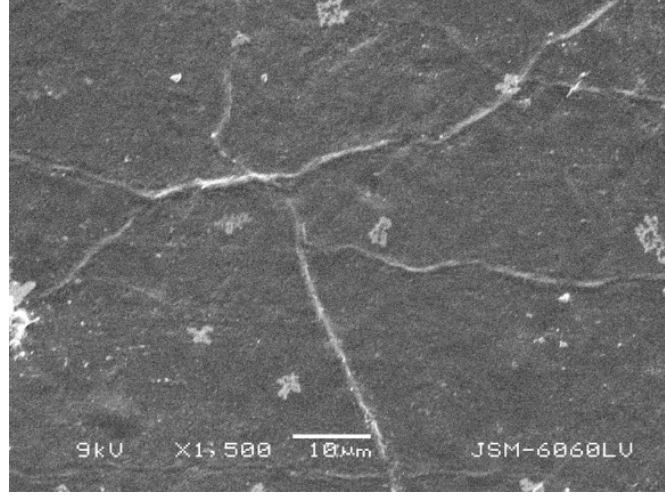

(b)

Figure 13. SEM images of photopolymer plate samples after swelling in IPA: (a) 10× UV treatment, (b) $30 \times$ UV treatment.

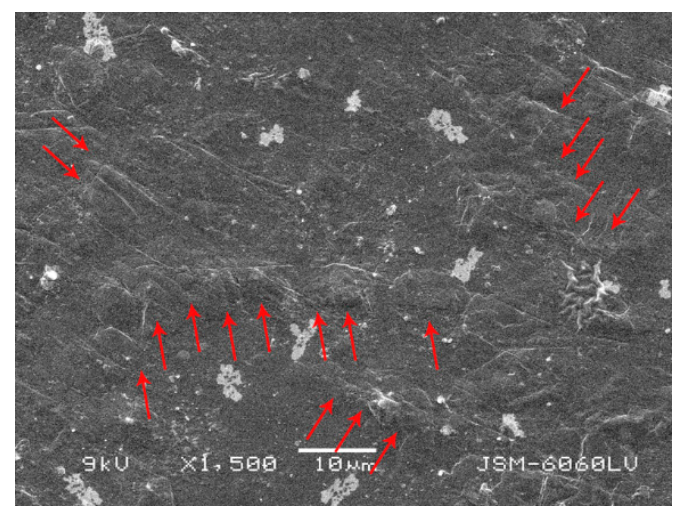

(a)

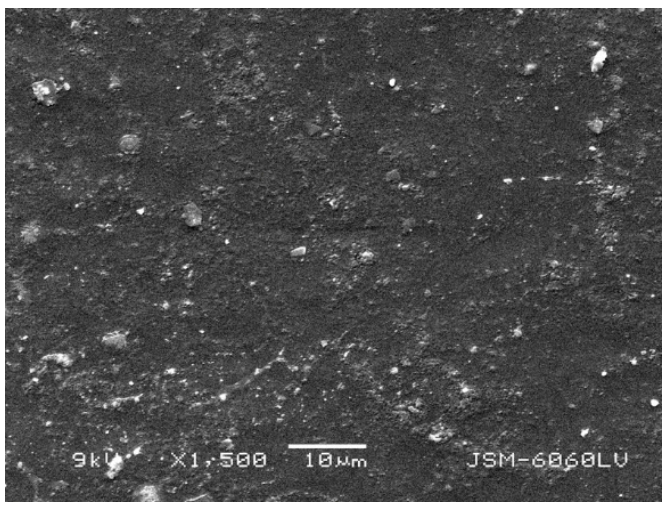

(b)

Figure 14. SEM images of photopolymer plate samples after swelling in Polywash: (a) $10 \times \mathrm{UV}$ treatment, (b) 30× UV treatment.

Changes of the surface morphology after the swelling in Polywash (Figure 14) are visually similar to the changes caused by methoxypropanol (Figure 12) but are less expressed. SEM images support the conclusion that Polywash has the lowest effect on the surface properties of the photopolymer printing plate among used solvents, once the photopolymer has been additionally treated by UV radiation (Figure 14b). Polywash mainly interacts with the polymer surface for lower durations of UV treatment (Figure 14a).

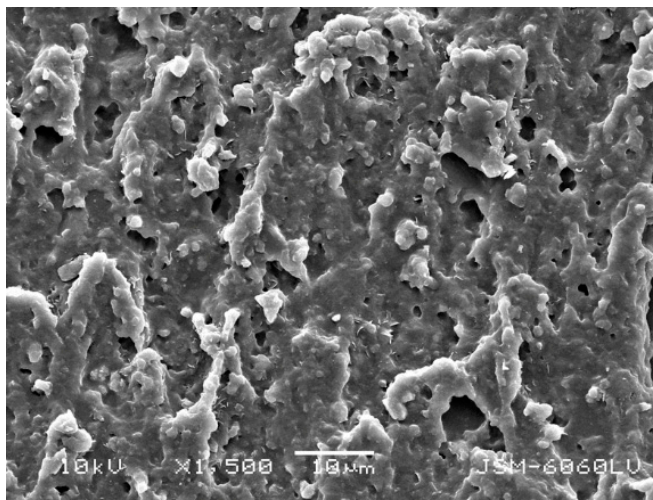

(a)

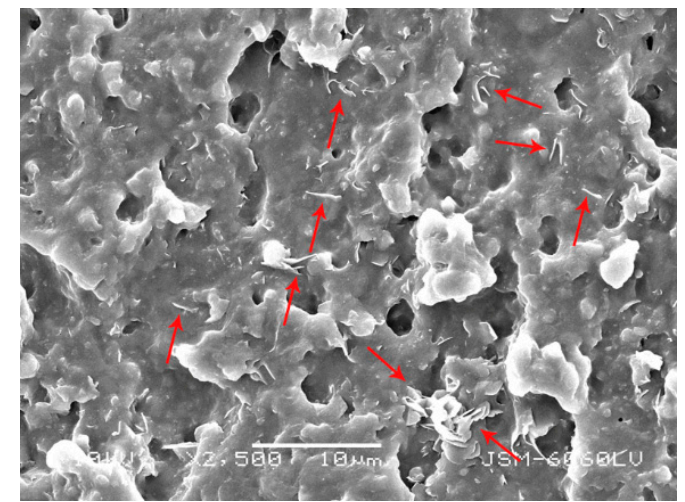

(b)

Figure 15. SEM images of EPDM plate samples after swelling in methoxypropanol: (a) $10 \times \mathrm{UV}$ treatment, (b) $30 \times$ UV treatment. 
Observing Figure 15a and comparing it to the same sample not immersed in any solvent (Figure 11b), it can be concluded that there are no significant changes in the surface morphology. Visual display of the effect of minor swelling is not as apparent on the porous surface as on the smooth photopolymer surface. The effect of methoxypropanol on the sample treated with $30 \times \mathrm{UV}$ (Figure 15b) is visible in form of the alterations of surface morphology marked by arrows. The effect could be explained by the migration of compounds/additives to the surface of EPDM, potentially the exposure of carbon black particles to the surface layer $[62,63]$. Carbon black is a common additive in vulcanized rubber and similar materials, its function being the enhancement of the mechanical properties (improved physical crosslinking) of the material [64].

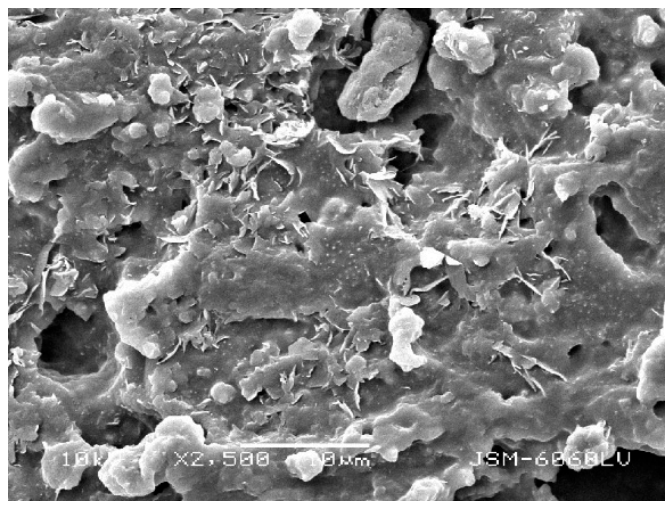

(a)

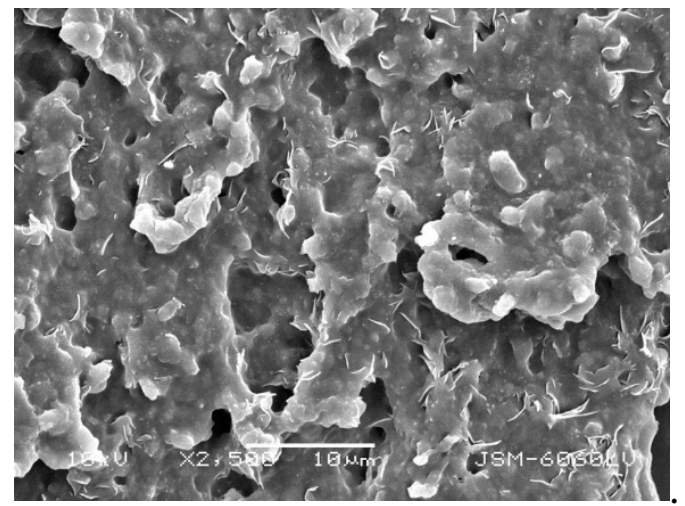

(b)

Figure 16. SEM images of EPDM plate samples after swelling in IPA: (a) 10× UV treatment, (b) 30× UV treatment.

Figure 16 presents the surfaces of EPDM after swelling in IPA. Swelling experiments have shown that a slight partial dissolution of EPDM in IPA takes place, but this is not undoubtedly observed in SEM images. However, the topography of the samples is likely more pronounced than in Figure $11 \mathrm{~b}$. The same artifacts as in Figure $15 \mathrm{~b}$ are visible.

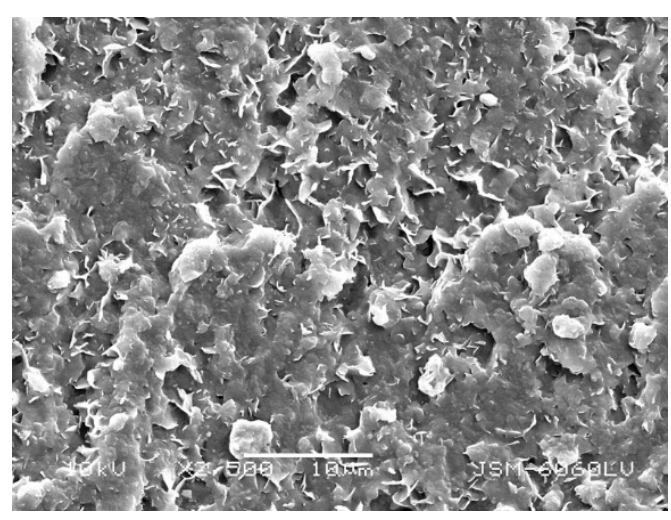

(a)

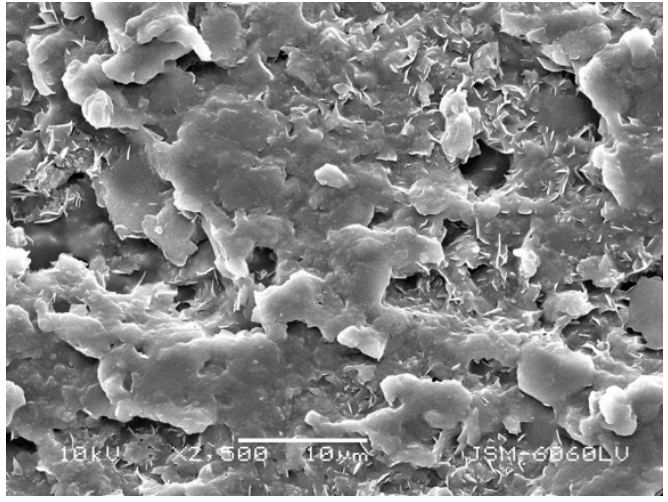

(b)

Figure 17. SEM images of EPDM plate samples after swelling in Polywash: (a) $10 \times$ UV treatment, (b) $30 \times$ UV treatment.

In Figure 17 one can see SEM images of EPDM after the swelling experiment in Polywash. The EPDM plate also proved to be resistant to Polywash in terms of swelling. Appearance of the surface is similar to Figure 16. However, since the exposure to Polywash caused the decrease of SFE compared to nominal, it can be concluded that the swelling of the printing plate does not necessarily predict the effect of the solvent on the surface, especially if the solvent is a poly-component, such as Polywash (Table 1). 
Specifically, when exposed to the UV radiation or solvent, the flexographic printing plate becomes a pronounced two-phase system, with modified surface properties depending on the surface interactions with the stimuli and the volume (core), which can undergo different changes to the surface, i.e., additional crosslinking caused by UV radiation [65].

\subsection{Width of the Printed Lines}

Figures 18 and 19 present the changes of the widths of fine lines printed by UV-treated printing plates after immersion in solvents, drying, and stabilization. Results are presented for lines with nominal width of $0.2 \mathrm{~mm}$, both in positive and negative.

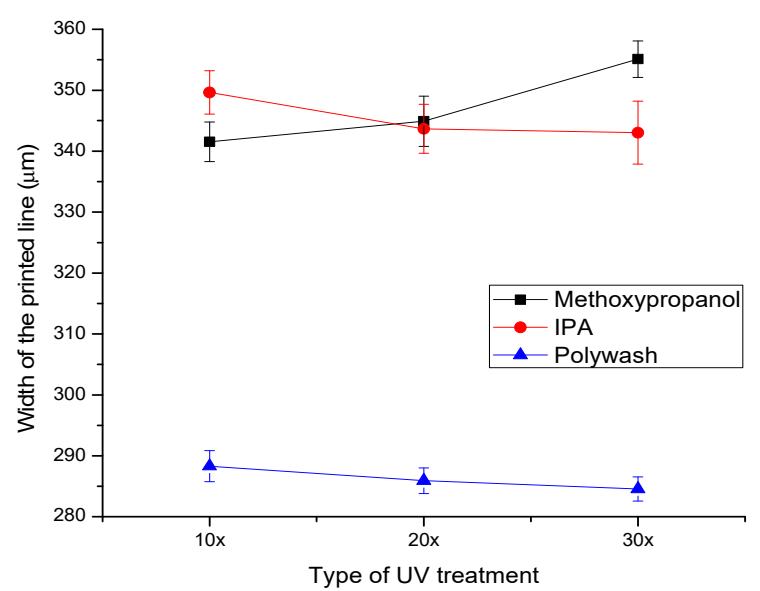

(a)

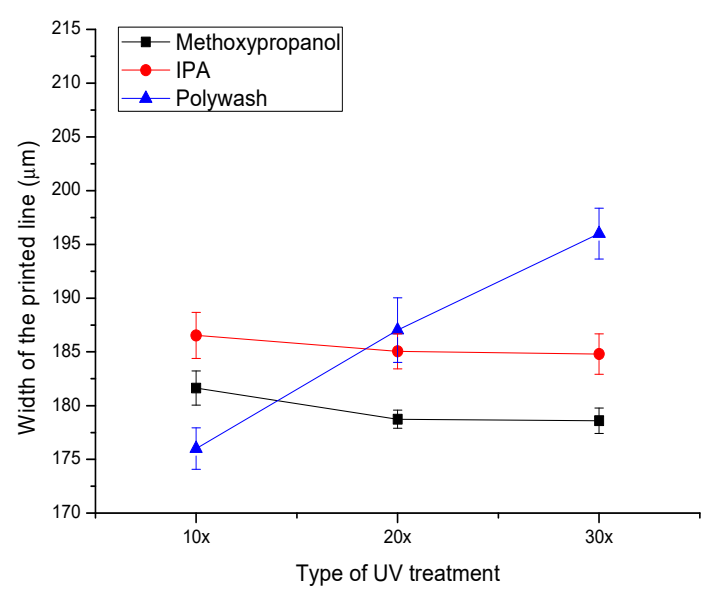

(b)

Figure 18. Width of the lines printed by modified photopolymer plates: (a) $0.2 \mathrm{~mm}$ positive, (b) $0.2 \mathrm{~mm}$ negative.

Observing Figure 18a, one can see that the measured width of the lines is higher than nominal for lines in positive, and lower than nominal for lines in negative. This is a common occurrence in flexography, since the printing plate elastically deforms during the printing process [29]. The expected and usual values and trend of the changes of line width are visible only for the sample treated by Polywash; as the duration of UV treatment increases along with the hardness of the printing plate, the deformation of the photopolymer becomes less prominent, and the width of the printed line in positive decreases. This is one of the reasons additional UV treatments can be beneficial in flexography. At the same time, the width of the printed line in negative should increase as the hardness of the plate increases. Lines printed by IPA-treated plate display a moderate decreasing trend for both positiveand negative-printed lines. Here, alongside the effect of the increased hardness, the interactions on the surface of the photopolymer and IPA are the crucial reason for the trend of the line printed in negative. As immersion of photopolymer samples in IPA resulted in pronounced increase of SFE (Figure 6), the wetting of the ink on the photopolymer improved, resulting in a slightly narrower printed line in negative (Figure 18b). Effect of the increased hardness after prolonged UV treatment is moderately observable for the line printed in positive.

The width of the line in positive printed by methoxypropanol-treated samples slightly increases with prolonged UV treatment. Width of the line after immersion in methoxypropanol is higher than the one obtained by Polywash-treated plate and the nominal width. This can be attributed to the pronounced swelling of the printing plate in methoxypropanol and its residue in the photopolymer after the drying process. For the same reasons, the width of the line printed in negative is too low. In this case, swelling properties of the plate and the influence of the solvent on the plate surface overcame the influence of the UV treatment on the plate's hardness. 


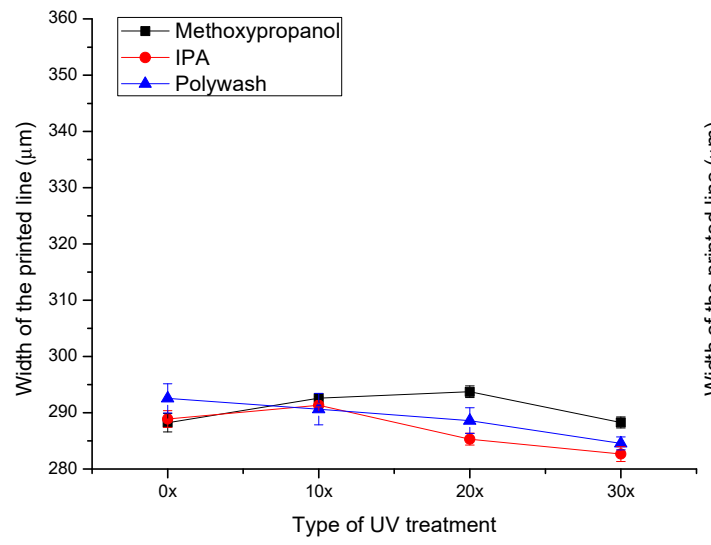

(a)

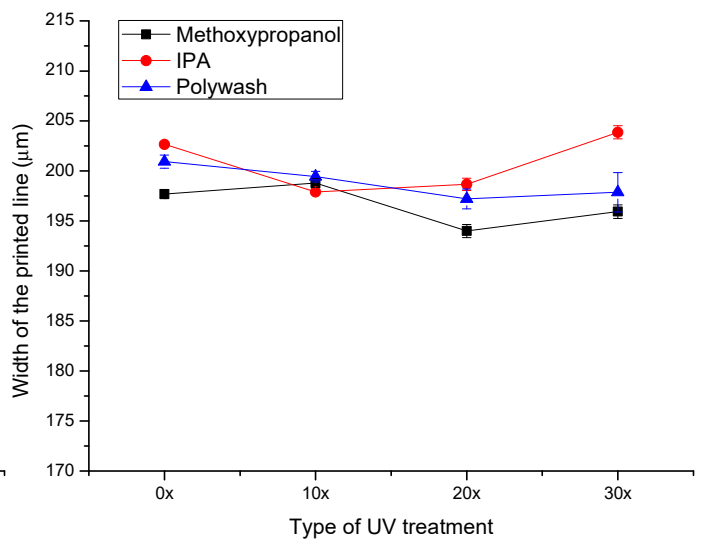

(b)

Figure 19. Width of the lines printed by modified EPDM plates: (a) $0.2 \mathrm{~mm}$ positive, (b) $0.2 \mathrm{~mm}$ negative.

Figure 19 presents the results of the width of printed lines obtained by modified EPDM printing plates. Compared to the lines printed by photopolymer plates (Figure 18), EPDM plates present values of the line widths closer to nominal $(0.2 \mathrm{~mm})$. This can be attributed to lower deformation of the engraved printing elements compared to photochemically obtained elements (Figures 1 and 2). Lower SFE of EPDM plates compared to photopolymer plates also disables the travelling of the ink down the element edges that causes the increased width of the printed line in positive/decreased printed line in negative. The widths of the lines printed in positive after swelling in IPA and Polywash decrease (Figure 19a) as an effect of the increased hardness of EPDM after additional UV treatments. Modest swelling of the EPDM plate in methoxypropanol resulted in the highest values of the line widths in positive. Lines printed in negative after swelling of plates display significant change only for the line printed in negative after 30× UV treatment and swelling in IPA (Figure 19b). This can be attributed to the highest increase of the hardness for this sample (Figure 5).

Figure 20 presents the line elements produced on the EPDM printing plate and the photopolymer printing plate.

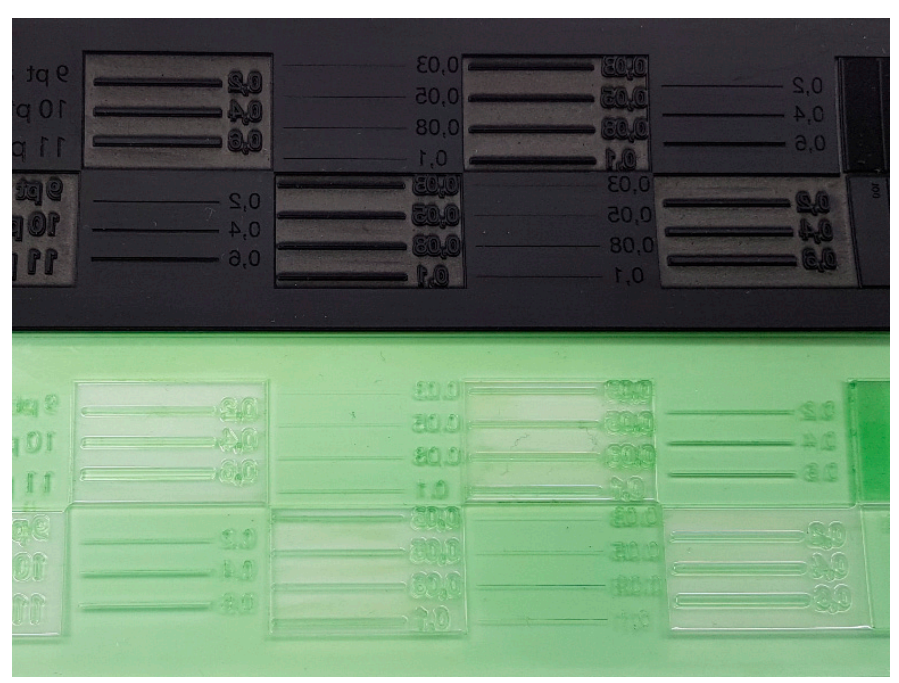

Figure 20. Line elements on EPDM plate (black) and photopolymer plate (green).

Figure 21 presents the examples of microscopic images of the thinnest lines that were printed by UV- and solvent-modified printing plates. The nominal width of the line in the original image file was $0.03 \mathrm{~mm}$. Lines were captured at magnification of $50 \times$. 


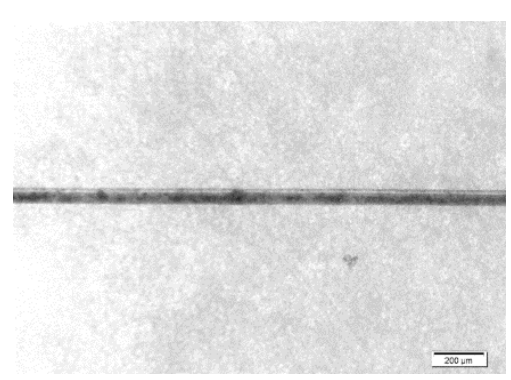

(a)

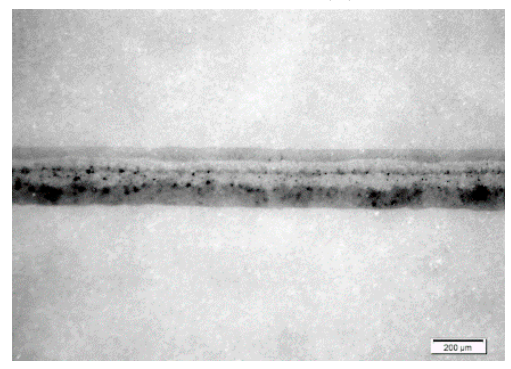

(c)

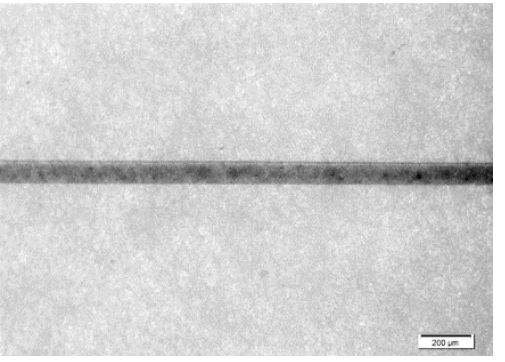

(b)

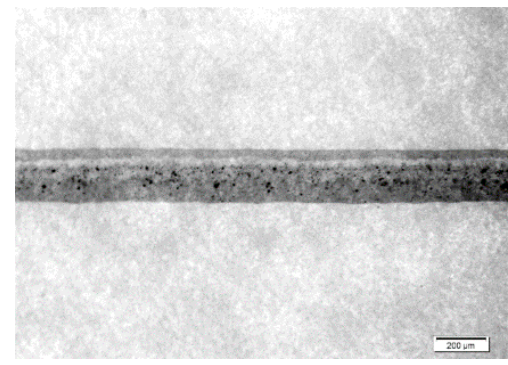

(d)

Figure 21. Lines of $0.03 \mathrm{~mm}$ nominal value fine lines printed by modified plates: (a) photopolymer 10×, methoxypropanol, (b) photopolymer 30×, methoxypropanol, (c) EPDM 10×, IPA, (d) EPDM 30×, IPA.

The widths of the lines presented in Figure 21 were not measured, since it is obvious that they did not print optimally, at least for the EPDM plate-the lines are too wide. The finest elements on flexographic plates are often not stable during the engagement in the printing process and are much more susceptible to deformations. However, the finest lines are presented in order to underline the importance of the printing plate hardness and the influence of swelling and to confirm the trends of the widths of correctly formed and stable wider lines (Figures 18 and 19).

In Figure 21a,b, the influence of methoxypropanol on the width of the line is clearly visible. The hardness of methoxypropanol-treated samples did not increase as a result of the UV treatments because of the pronounced swelling (Figure 4). Since SFE of the plate increased for the sample treated with $30 \times$ UV treatment (Figure 6), ensuring the improved wetting of the ink on the plate, the width of the line increased. The same effect is present in Figure 18a for the $0.2 \mathrm{~mm}$ line.

In Figure 21d, the decreased line width for the sample treated with $30 \times \mathrm{UV}$ treatment and immersed in IPA is visible compared to the $10 \times$ sample immersed in IPA (Figure 21c). The same effect is present for the $0.2 \mathrm{~mm}$ line (Figure 19a). Since hardness of the EPDM material is the only parameter that changed noticeably, i.e., increased (Figure 5), its effect on the line width is obvious.

\subsection{Thickness of the Printed Ink Film}

Figure 22 presents the results of the deposited ink film thickness obtained by modified EPDM and photopolymer printing plates.

When depositing the ink film in flexography (with ink coverage on the surface of 100\%), SFE of the printing plate displays its influence on the thickness of the ink film significantly [43,57]. For the photopolymer plate (Figure 22a), the ink film thickness decreases as SFE of the plate increases (Figure 6). With the increase of SFE, the wetting of the printing ink on the plate improves, thus creating and transferring the thinner ink film onto the printing substrate. Increased hardness of the printing plate also contributes to the decreased deposited ink film, since the harder plate does not deform elastically that much in the printing process. The only sample that does not follow the trend of decreasing of ink film thickness is the one printed by $20 \times$ UV-treated plate after swelling in methoxypropanol. This occurred because SFE of that sample decreased due to the migrations and alterations of the plate 
surface after the exposure to UV radiation and methoxypropanol. Thickness of the ink film printed by this set of samples ranges from $4 \mu \mathrm{m}$ to $1.2 \mu \mathrm{m}$.

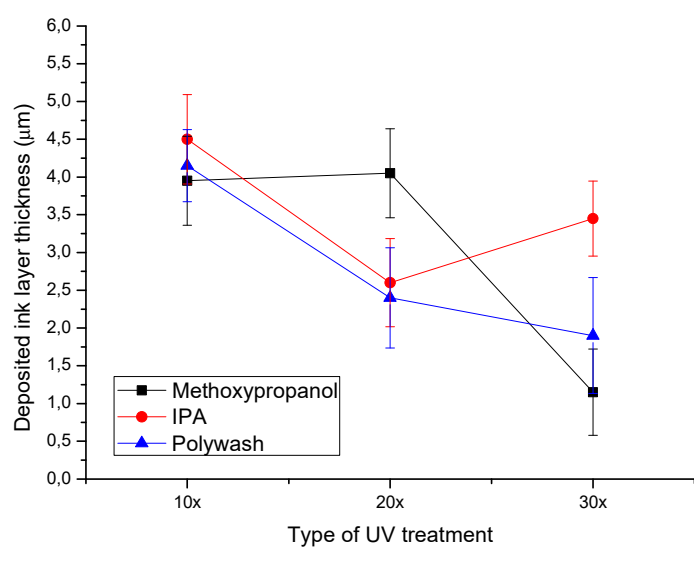

(a)

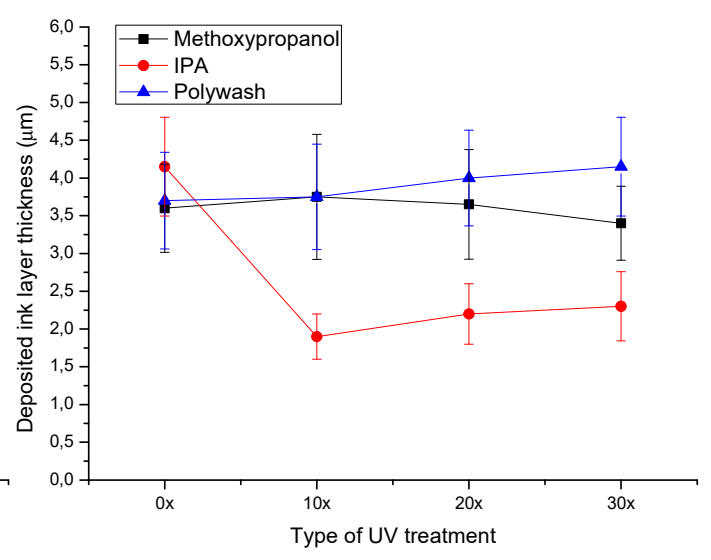

(b)

Figure 22. Thickness of ink film deposited by modified printing plates: (a) Photopolymer plate, (b) EPDM plate.

Trends of the changes of ink film thickness obtained by the EPDM plate (Figure 22b) also correspond inversely to the changes of the plate's SFE (Figure 7). The most pronounced decrease of the ink film thickness is visible for the prints obtained by the samples exposed to IPA, since these samples show the highest increase of SFE. Ink film thickness for this sample decreases from $4.2 \mu \mathrm{m}$ to $2.3 \mu \mathrm{m}$. Since EPDM plates are recommended for use in systems with various solvents, such as in applications of special inks, one must be aware of the effect of the solvents on the surface properties of this type of printing plate.

Finally, Tables 2 and 3 present the summary of the results obtained by all printing plate samples that have been UV-treated and exposed to the solvents (see Supplementary Materials). The results include analyzed properties of the printing plates as well as the properties of obtained prints.

Table 2. Summary of results obtained with photopolymer printing plates.

\begin{tabular}{|c|c|c|c|c|c|c|c|}
\hline \multirow{2}{*}{ Solvent } & \multicolumn{7}{|c|}{ Photopolymer Printing Plate } \\
\hline & $\begin{array}{c}\text { UV } \\
\text { Treatment }\end{array}$ & $\begin{array}{l}\text { Hardness } \\
\text { (Shore A) }\end{array}$ & $\begin{array}{c}\mathrm{SFE} \\
(\mathrm{mN} / \mathrm{m})\end{array}$ & $\begin{array}{c}\text { Max. Normalized } \\
\text { Degree of } \\
\text { Swelling (\%) }\end{array}$ & \multicolumn{2}{|c|}{$\begin{array}{l}\text { Line Width } \\
\text { (mm) }\end{array}$} & $\begin{array}{c}\text { Printed Ink } \\
\text { Film Thickness } \\
(\mu \mathrm{m})\end{array}$ \\
\hline Methoxy-propanol & $10 x$ & 73.64 & 30.51 & 5.24 & 341.53 & 181.63 & 3.95 \\
\hline \multirow{3}{*}{ 2-propanol (IPA) } & $10 x$ & 73.95 & 28.24 & 1.63 & 349.63 & 186.53 & 4.50 \\
\hline & $20 \times$ & 76.85 & 36.15 & 1.66 & 343.60 & 185.07 & 2.60 \\
\hline & $30 \times$ & 76.83 & 36.76 & 1.17 & 343.03 & 184.80 & 3.45 \\
\hline \multirow[b]{2}{*}{ Polywash } & $10 x$ & 73.41 & 25.03 & 1.92 & 288.37 & 176.00 & 4.15 \\
\hline & $20 \times$ & 75.00 & 32.70 & 2.08 & 285.97 & 187.03 & 2.40 \\
\hline
\end{tabular}


Table 3. Summary of results obtained with EPDM printing plates.

\begin{tabular}{|c|c|c|c|c|c|c|c|}
\hline \multirow{3}{*}{ Solvent } & \multirow{3}{*}{$\begin{array}{c}\text { UV } \\
\text { Treatment }\end{array}$} & \multirow{3}{*}{$\begin{array}{l}\text { Hardness } \\
\text { (Shore A) }\end{array}$} & \multirow{3}{*}{$\begin{array}{c}\text { SFE } \\
(\mathrm{mN} / \mathrm{m})\end{array}$} & \multicolumn{3}{|c|}{ EPDM Printing Plate } & \multirow{3}{*}{$\begin{array}{c}\text { Printed Ink } \\
\text { Film Thickness } \\
(\mu \mathrm{m})\end{array}$} \\
\hline & & & & \multirow{2}{*}{$\begin{array}{c}\text { Max. Normalized } \\
\text { Degree of } \\
\text { Swelling (\%) }\end{array}$} & \multicolumn{2}{|c|}{$\begin{array}{l}\text { Line Width } \\
\quad(\mathrm{mm})\end{array}$} & \\
\hline & & & & & $\begin{array}{c}0.2 \\
\text { Positive }\end{array}$ & $\begin{array}{c}0.2 \\
\text { Negative }\end{array}$ & \\
\hline \multirow{4}{*}{ Methoxy-propanol } & $0 \times$ & 70.12 & 20.10 & 0.24 & 288.23 & 197.7 & 3.60 \\
\hline & $10 x$ & 72.70 & 14.86 & 0.25 & 292.60 & 198.8 & 3.75 \\
\hline & $20 x$ & 72.71 & 15.87 & 0.34 & 293.73 & 194.00 & 3.65 \\
\hline & $30 \times$ & 72.67 & 19.53 & 0.23 & 288.27 & 195.93 & 3.40 \\
\hline \multirow{4}{*}{ 2-propanol (IPA) } & $0 \times$ & 69.71 & 11.35 & -0.10 & 288.90 & 202.67 & 4.15 \\
\hline & $10 x$ & 72.53 & 23.43 & -0.05 & 291.32 & 197.90 & 1.90 \\
\hline & $20 x$ & 72.82 & 23.60 & -0.07 & 285.30 & 198.67 & 2.20 \\
\hline & $30 \times$ & 73.28 & 23.99 & -0.09 & 282.67 & 203.87 & 2.30 \\
\hline \multirow{4}{*}{ Polywash } & $0 \times$ & 69.68 & 14.45 & 0.24 & 292.57 & 200.93 & 3.70 \\
\hline & $10 x$ & 72.76 & 14.96 & 0.47 & 290.63 & 199.43 & 3.75 \\
\hline & $20 x$ & 72.77 & 12.44 & 0.42 & 288.60 & 197.20 & 4.00 \\
\hline & $30 \times$ & 72.70 & 12.40 & 0.43 & 284.57 & 197.87 & 4.15 \\
\hline
\end{tabular}

\section{Conclusions}

The aim of this research was to analyze and improve the resistance of photopolymer and EPDM flexographic printing plates to common solvents used during the ink deposition process. In order to achieve that, printing plates were additionally treated by UV radiation prior to the swelling experiments in solvents, with the aim of increasing their crosslinking degree and possibly optimizing their surface properties. The influences of three common solvents on the properties of printing plates and corresponding prints were analyzed. Results of the research prove that the additional UV treatment can be used to increase the hardness of printing plates and thereby optimize the width of the fine printed lines after the plates have been exposed to solvents. The EPDM plate presented more resistance to the influence of all used solvents in terms of the changes in the width of the fine printed lines and their deviations from the nominal values. Changes in surface free energy as a consequence of the swelling experiments after UV treatments were significant for both photopolymer and EPDM plates. Modified surface free energy primarily affected the thickness of the printed ink film for all plate samples. Therefore, it can be concluded that the choice of the printing plate material and careful adjustment of the additional UV treatment of the printing plate can be used to optimize the properties of the printed ink film. This research has underlined the need to recognize that the effect of specific solvents on the printing plate material can be different for fine printing elements/details on print and the solid ink film area. Depending on the properties and purpose of the image to be printed, optimization of the printing process regarding the printing plate material and the choice of the printing ink/cleaning solvent should be considered.

Supplementary Materials: Supplementary materials are available online at http://www.mdpi.com/2079-6412/10/ 2/136/s1

Author Contributions: Investigation, S.M.P. and T.T.; methodology and experiment, T.T., S.M.P. and M.S.J.; formal analysis, T.T., S.M.P., R.U. and M.S.J.; SEM analysis, R.U.; writing-original draft preparation, S.M.P and T.T.; references, M.S.J. All authors have read and agreed to the published version of the manuscript.

Funding: This research received funding from University of Zagreb—short term grants for scientific research, title: "Optimization of workflow and modification of printing plates for packaging reproduction".

Conflicts of Interest: The authors declare no conflict of interest.

\section{References}

1. Sun, J.; Cui, B.; Chu, F.; Yun, C.; He, M.; Li, L.; Song, Y. Printable nanomaterials for the fabrication of high-performance supercapacitors. Nanomaterials 2018, 8, 528. [CrossRef] 
2. Sun, J.; Yun, C.; Cui, B.; Li, P.; Liu, G.; Wang, X.; Chu, F. A Facile Approach for Fabricating Microstructured Surface Based on Etched Template by Inkjet Printing Technology. Polymers 2018, 10, 1209. [CrossRef]

3. Bodwell, R.; Scharfenberg, J. Advancing Flexography: The Technical Path Forward. Available online: http://www.intermarketcorp.com/images/business/PosWhitePaper4-11.pdf (accessed on 3 February 2020).

4. Cosnahan, T.; Watt, A.A.; Assender, H.E. Flexography Printing for Organic Thin Film Transistors. Mater. Today Proc. 2018, 5, 16051-16057. [CrossRef]

5. Lorenz, A.; Senne, A.; Rohde, J.; Kroh, S.; Wittenberg, M.; Krüger, K.; Clement, F.; Biro, D. Evaluation of Flexographic Printing Technology for Multi-Busbar Solar Cells. Energy Procedia 2015, 67, 126-134. [CrossRef]

6. Joyce, M.; Pal, L.; Hicks, R.; Agate, S.; Williams, T.S.; Ray, G.; Fleming, P.D. Custom tailoring of conductive ink/substrate properties for increased thin film deposition of poly(dimethylsiloxane) films. J. Mater. Sci. Mater. Electron. 2018, 29, 10461-10470. [CrossRef]

7. Alem, S.; Graddage, N.; Lu, J.; Kololuoma, T.; Movileanu, R.; Tao, Y. Flexographic printing of polycarbazole-based inverted solar cells. Org. Electron. 2018, 52, 146-152. [CrossRef]

8. Rentzhog, M. Water-Based Flexographic Printing on Polymer-Coated Board. Ph.D. Thesis, Royal Institute of Technology, Stockholm, Sweden, 2006.

9. Izdebska, J.; Sabu, T. Printing on Polymers: Fundamentals and Applications; Elsevier: Amsterdam, The Netherlands, 2015; ISBN 9788578110796. [CrossRef]

10. Cruz, S.M.F.; Rocha, L.A.; Viana, J.C. Printing Technologies on Flexible Substrates for Printed Electronics. IntechOpen 2018, 1, 47-70. [CrossRef]

11. Bornemann, N.; Sauer, H.M.; Dörsam, E. Gravure printed ultrathin layers of small-molecule semiconductors on glass. J. Imag. Sci. Technol. 2011, 55, 040201. [CrossRef]

12. Joshi, A.V.; Dettke, C.; Steingraeber, J. Investigation on electrostatic assist and gravure process parameters on solid mottle reduction for shrink films. J. Coat. Technol. Res. 2016, 13, 375-383. [CrossRef]

13. Hyun, W.J.; Secor, E.B.; Hersam, M.C.; Frisbie, C.D.; Francis, L.F. High-resolution patterning of graphene by screen printing with a silicon stencil for highly flexible printed electronics. Adv. Mater. 2015, 27, 109-115. [CrossRef]

14. Andersson, C.; Johnson, J.; Järnström, L. Ultraviolet-induced aging of flexographic printing plates studied by thermal and structural analysis methods. J. Appl. Polym. Sci. 2009, 112, 1636-1646. [CrossRef]

15. Todd, R.E. Printing Inks: Formulation Principles, Manufacture and Quality Control Testing Procedures; Pira International: London, UK, 1994.

16. Speirs, H.M. Introduction to Printing and Finishing; British Printing Industries Federation and Pira International: London, UK, 2003; ISBN 10: 1858029066; ISBN 13: 9781858029061.

17. Cusdin, G. Flexography: Principles E Practices, 5th ed.; Foundation of Flexographic Technical Association: Ronkonkoma, NY, USA, 1999.

18. Hamblyn, A. Effect of Plate Characteristics on Ink Transfer in Flexographic Printing. Ph.D. Thesis, Swansea University, Swansea, UK, 2015; pp. 2-5.

19. Thompson, B. Printing Materials: Science and Technology (Pira Printing Guide Series); Pira International: Surrey, UK, 1998.

20. Rentzhog, M.; Fogden, A. Correlations between properties of water-based flexographic inks and their print uniformity on PE-coated board. Nord. Pulp Pap. Res. J. 2006, 21, 403-410. [CrossRef]

21. Bohlin, E.; Lestelius, M.; Johansson, C. Flexographic ink-coating interactions - Effects of porous structure variations of coated paperboard. Nord. Pulp Pap. Res. J. 2013, 28, 573-581. [CrossRef]

22. Peters, A.C.I.; Overbeek, G.; Annable, T. Bimodal particle size distribution polymer/oligomer combinations for printing ink applications. Prog. Org. Coat. 2000, 38, 137-150. [CrossRef]

23. Tipsotnaiyana, N.; Jarupan, L.; Noppakundilograt, S. Enhancement of flexographic print quality on bleached kraft liner using nano-silica from rice husk. Prog. Org. Coat. 2015, 87, 232-241. [CrossRef]

24. INTERGRAF (International Confederation for Printing and Allied Industries). Flexography and Packaging Gravure. Available online: https:/ec.europa.eu/environment/archives/air/stationary/solvents/activities/pdf/ 155_en.pdf (accessed on 3 February 2020).

25. Mantis, D.; Dfh, D. Solvent Based Printing Inks. Available online: https://ocp.teiath.gr > TGT_UNDER100 > $\Pi \propto \rho o v \sigma \iota \alpha ́ \sigma \varepsilon \iota \varsigma$ (accessed on 3 February 2020).

26. Jenkins, J. The Effects of Common Solvents on Different Types of Flexographic Printing Plates. Ph.D. Thesis, Rochester Institute of Technology, New York, NY, USA, 1985. 
27. Poljacek, S.M.; Cigula, T.; Tomasegovic, T.; Brajnović, O. Meeting the quality requirements in the flexographic plate making process. Int. Circ. Graph. Educ. Res. 2013, 6, 62-68.

28. Foundation of Flexographic Technical Association. FIRST, Flexographic Image Reproduction Specifications $\mathcal{E}$ Tolerance, 3rd ed.; Foundation of Flexographic Technical Association: New York, NY, USA, 2003.

29. Johnson, J. Aspects of Flexographic Print Quality and Relationship to Some Printing Parameters; Karlstad University: Karlstad, Sweden, 2008; ISBN 9789170631870.

30. Galton, D.; Bould, D.; Claypole, T. The effect of surface properties on the printability of flexographic printing plates. Adv. Print. Media Technol. 2010, 37, 277-283.

31. Poljaček, S.M.; Tomašegović, T.; Cigula, T.; Gojo, M.; Milčić, D. Formation of the printing elements in the photopolymer material used in flexography. Key Eng. Mater. 2014, 611-612, 883-891.

32. Tomašegović, T.; Poljaček, S.M.; Leskovac, M. UVA and UVC modification of photo polymeric surface and application for flexographic deposition of thin coatings. J. Appl. Polym. Sci. 2016, 133, 43526. [CrossRef]

33. Tomašegović, T.; Beynon, D.; Claypole, T.; Poljaček, S.M. Tailoring the properties of deposited thin coating and print features in flexography by application of UV-ozone treatment. J. Coat. Technol. Res. 2016, 13, 815-828. [CrossRef]

34. Flint Group, nyloflex®ACE Digital. Available online: https://www.flintgrp.com/media/1296/nyloflex_ace_ en.pdf (accessed on 3 February 2020).

35. Knöll, R. Photopolymerizable Flexographic Printing Elements Comprising SIS/SBS Mixtures as Binder for the Production of Flexographic Printing Plates. U.S. Patent 6,531,263, 11 March 2003.

36. Lee, T.Y.; Guymon, C.A.; Jönsson, E.S.; Hoyle, C.E. The effect of monomer structure on oxygen inhibition of (meth)acrylates photopolymerization. Polymer 2004, 45, 6155-6162. [CrossRef]

37. Cushner, S.; Fan, R.N.; Leberzammer, E.; Shea, P.T.; Zoeren, C.M. Van Laser Engravable Single-Layer Flexographic Printing Element. U.S. Patent 5,798,202, 25 August 1998.

38. Burberry, M.S.; Tutt, L.W.; Rowley, L.A. System for Direct Engraving of Flexographic Printing Members. U.S. Patent 8,941,028, 27 January 2015.

39. The New Conti Laserline Flexographic Printing Plate. Available online: https://www.conti-laserline.com/ pages/produkte/know-how/digital/digital_en.html (accessed on 3 February 2020).

40. Birkan Laser Engraved Elastomer Printing Plates. Available online: https://www.birkan.de/pdf/en/BIRKAN_ Laser-engraved-elastomer-printing-plates_en.pdf (accessed on 3 February 2020).

41. Mogg, B.T.; Claypole, T.; Deganello, D.; Phillips, C. Flexographic printing of ultra-thin semiconductor polymer layers. Transl. Mater. Res. 2016. [CrossRef]

42. Aktiprint L - Technigraf. Available online: http://en.technigraf.de/portfolio/aktiprint-1/ (accessed on 3 February 2020).

43. Tomašegović, T. Functional Model of Photopolymer Printing Plate. Ph.D. Thesis, University of Zagreb Faculty of Graphic Arts, Zagreb, Croatia, 2016.

44. National Center for Biotechnology Information. 1-Methoxy-2-propanol, CID=7900. Available online: https://pubchem.ncbi.nlm.nih.gov/compound/1-Methoxy-2-propanol (accessed on 3 February 2020).

45. National Center for Biotechnology Information. PubChem Database. Isopropyl Alcohol, CID=3776. Available online: https://pubchem.ncbi.nlm.nih.gov/compound/Isopropyl-alcohol (accessed on 3 February 2020).

46. Hansen, C.M. Hansen Solubility Parameters: A User's Handbook, 2nd ed.; CRC Press: Boca Raton, FL, USA, 2007.

47. Liu, J.; Zheng, X.J.; Tang, K.Y. Study on the gravimetric measurement of the swelling behaviors of polymer films. Rev. Adv. Mater. Sci. 2013, 33, 452-458.

48. ISO 7619-1:2010 Rubber, Vulcanized or Thermoplastic-Determination of Indentation Hardness—Part 1: Durometer Method (Shore Hardness). Available online: https://www.iso.org/obp/ui/\#iso:std:iso:48:-4:ed-1: v1:en (accessed on 3 February 2020).

49. OCA Product Series. Available online: https://www.dataphysics-instruments.com/Downloads/OCA_EN. pdf?v=1.4 (accessed on 3 February 2020).

50. Van Oss, C.J.; Giese, R.F.; Li, Z.; Murphy, K.; Norris, J.; Chaudhury, M.K.; Good, R.J. Contact Angle, Wettability and Adhesion; Mittal, K.L., Ed.; VSP: Utrecht, The Netherlands, 1993; pp. 269-284.

51. Owens, D.K.; Wendt, R.C. Estimation of the surface free energy of polymers. J. Appl. Polym. Sci. 1969, 13, 1741-1747. [CrossRef]

52. IGT Testing Systems Pte Ltd. IGT Printability Tester F1. Available online: http://www.igt.com.sg/products/ details/igt-printability-tester-f1-f1-basic-f1-uv-f1-corrugated-f1-100 (accessed on 3 February 2020). 
53. User Manual. Coating Thickness Gauge. SaluTron(C) D4/D5. Available online: https://www.salutron.de/ fileadmin/redakteure/dokumente/Instruction-manual-SaluTron-D4-5.pdf (accessed on 3 February 2020).

54. Poljaček, S.M.; Tomašegović, T.; Gojo, M. Influence of UV exposure of the surface and mechanical properties of flexographic printing plate. In Proceedings of the GRID 2012 Symposium, Novi Sad, Serbia, 15-16 November 2012; pp. 135-140.

55. Abu-Abdeen, M.; Elamer, I. Mechanical and swelling properties of thermoplastic elastomer blends. Mater. Des. 2010, 31, 808-815. [CrossRef]

56. Haseeb, A.S.M.A.; Jun, T.S.; Fazal, M.A.; Masjuki, H.H. Degradation of physical properties of different elastomers upon exposure to palm biodiesel. Energy 2011, 36, 1814-1819. [CrossRef]

57. Poljaček, S.M.; Tomašegović, T.; Leskovac, M.; Jakovljević, S. Neural network-based UV adjustment of the photopolymer surface for modification of coating properties printed in flexography. J. Coat. Technol. Res. 2019, 17, 271-284. [CrossRef]

58. Chen, X.; Wang, J.; Shen, J. Effect of UV-irradiation on poly(vinyl chloride) modified by methyl methacrylate-butadiene-styrene copolymer. Polym. Degrad. Stab. 2005, 87, 527-533. [CrossRef]

59. Simseker, O. Investigation of different solvents in flexographic printing ink's effects to print quality on coated and uncoated paper. Asian J. Chem. 2011, 23, 2903-2906.

60. Tomašegović, T.; Mahović Poljaček, S.; Leskovac, M. Customization of flexographic printing plates related to uvc-induced changes in the crosslinking degree. Acta Graph. J. Print. Sci. Graph. Commun. 2016, 27, 31-42.

61. Apaya, R.P.; Bondi, M.; Price, S.L. The orientation of $\mathrm{N}-\mathrm{O}=\mathrm{C}$ and N-N hydrogen bonds in biological systems: How good is a point charge as a model for a hydrogen bonding atom? J. Comput. Aided. Mol. Des. 1997, 11,479-490. [CrossRef] [PubMed]

62. Satpati, A.K.; Bard, A.J. Preparation and characterization of carbon powder paste ultramicroelectrodes as tips for scanning electrochemical microscopy applications. Anal. Chem. 2012, 84, 9498-9504. [CrossRef] [PubMed]

63. Vasconcelos, G.; Chagas, D.C.; Campos, D.C.; Dias, A.N. Covering with carbon black and thermal treatment by a $\mathrm{CO}_{2}$ laser surfaces of AISI 4340 steel. Mater. Sci. Forum 2012. [CrossRef]

64. Li, Z.H.; Zhang, J.; Chen, S.J. Effects of carbon blacks with various structures on vulcanization and reinforcement of filled ethylene-propylene-diene rubber. Exp. Polym. Lett. 2008, 2, 695-704. [CrossRef]

65. Deflorian, F.; Fedrizzi, L.; Rossi, S. Electrochemical Impedance Spectroscopy and Fourier Transform Infrared Spectroscopy of Natural and Accelerated Weathering of Organic Coatings. Corrosion 1998. [CrossRef] 